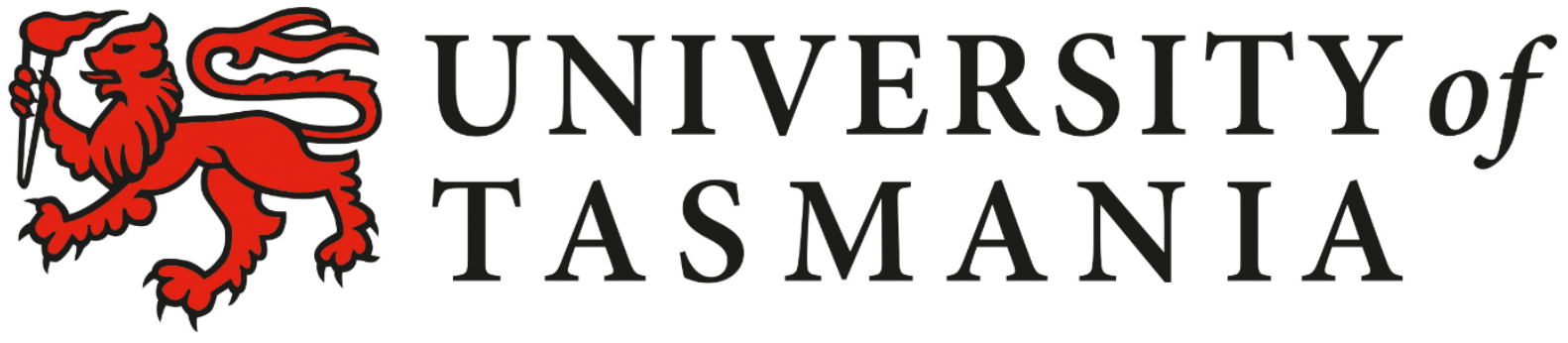

The Contribution of Parents in Childhood Anxiety Treatment: A meta-analytic review

By

Amy Carnes

A report submitted as a partial requirement for the degree of Bachelor of Psychological Sciences with Honours.

Division of Psychology, School of Medicine

University of Tasmania

October 2017 


\section{Statement of Sources}

I declare that this report is my own original work and that contributions of others have been duly acknowledged.

Signed:

Date: 


\section{Acknowledgements}

Firstly, I would like to acknowledge my supervisor Dr. Mandy Matthewson. Thank you for accepting the challenge of adding me as an Honours student to your numerous existing demands at the last minute. Thank you for sharing with me all that you know, your second opinions and proof-reads were truly invaluable. Additionally, I would like to thank Olivia Boer for the initial groundwork and her help with getting me started with the project.

I am also eternally grateful to all my family and friends. To my parents Wayne and Kim, thank you for always encouraging me no matter what and supporting me whenever and whatever challenges arose. Without you, none of this would have been possible. To Alec and Olivia thank you for all your support and inspiring me to choose a helping profession.

To my partner Brett, words cannot describe how supportive and loving you have been throughout not only this year but the past six years you have been in my life. I do not think you know how much you have contributed to getting me to where I am today, and I am forever indebted. To Emily my best friend thanks so much for staying by me and being supportive of me through all my absences and your own challenges. To all my other friends who have greeted me with open arms despite my long absences, thank you.

I would also like to express my immense gratitude to my fellow Honours students, Ruby and Scarlett. You two have had an enormous impact on my life over the past few years and have made the last year achievable, you listened to my endless complaints, dealt with my impatience and supported me day or night and for all that and more I thank you both. To the other Honours students in my cohort, thank you all for making this year so fun and collegial.

Thank you to all the researchers within the field for all their hard work and special thanks to all the individuals who participated in the studies reviewed and cited here. Finally, thank you to all the UTAS psychology staff for all your assistance and knowledge. 


\section{Table of Contents}

Acknowledgements $\quad$ iii

List of Tables $\quad$ vi

List of Figures vi

Abstract 2

Introduction 3

Anxiety Defined 3

Cognitive Behavioural Therapy for Childhood Anxiety: 4

A Case for Parental Inclusion

Existing Literature and the Child-Only vs Parental

Inclusion Debate

Advantages of Systematic Reviews and Meta-Analyses $\quad 10$

Rationale and Aims $\quad 11$

$\begin{array}{ll}\text { Method } & 12\end{array}$

$\begin{array}{ll}\text { Design } & 12\end{array}$

$\begin{array}{lr}\text { Procedure and Search Strategy } & 12\end{array}$

Study Inclusion Criteria 13

Data Extraction $\quad 15$

Assessment of Risk of Bias in the Included Studies $\quad 16$

Data Analysis 16

Time-point measures. 17

Anxiety-based outcome data. 18

Effect size measure. $\quad 19$

Meta-analytic method. 19

Assessment of heterogeneity. 20

$\begin{array}{ll}\text { Results } & 22\end{array}$

Systematic Review of the Literature 22

$\begin{array}{lr}\text { Summary of Bias } & 26\end{array}$

Overall Effectiveness of PCBT and ICBT for Childhood Anxiety 
Analysis One: Immediately Post-Treatment MetaAnalysis

Analysis Two: One-Year Post-Treatment Follow-Up

Meta-Analysis

Analysis Three: Time-Point Subgroup Analysis

Discussion

Summary of Findings

Literature review.

Efficacy of PCBT and ICBT.

Advantage of PCBT over ICBT.

Alternative explanations to current findings.

Moderators of the Current and Existing Findings

Implications for Practice

\section{References}

Appendices

Appendix A Prisma Checklist

Appendix B Search Terms by Database

Appendix C Data Extraction Form 56

Appendix D Risk of Bias Graph 


\section{List of Tables}

Table 1. Summary of Reviewed Articles

\section{List of Figures}

Figure 1. PRISMA flow diagram depicting the literature search and selection process

Figure 2. Analysis One: Immediately post-treatment analysis and forest plot

Figure 3. Analysis Two: One-year post-treatment follow-up analysis and forest plot 
The Contribution of Parents in Childhood Anxiety Treatment: A meta-analytic review

By

Amy Carnes

Word Count: 9,064 


\begin{abstract}
The current study systematically reviewed the literature pertaining to childhood anxiety treatment, to clarify if involving parents in treatment (PCBT) is more effective than child only treatments (ICBT). PsychINFO, PubMed, Web of Science, Embase and The Cochrane Library were searched. Five articles met inclusion criteria and compared a PCBT that had mother and father involvement to an ICBT. Two meta-analyses comparing PCBT and ICBT on the number of children free from their anxiety disorder immediately post-treatment and one-year post-treatment follow-up were conducted. At the immediately post-treatment analysis, significant and moderate to high heterogeneity was found. No significant advantage for PCBT or ICBT was observed for either time-point analysis. Upon comparison of analyses, no significant difference between time-points for either treatment was found. Results suggest that PCBT and ICBT are equally efficacious childhood anxiety treatments with no delayed effects. It is recommended that clinicians consider the need to include parents on a case-by-case basis. Future research should attempt to include both mothers and fathers in any parental interventions. The current findings are limited by the quality and methodology of the existing literature and should be considered in respect of this.
\end{abstract}




\section{Anxiety Defined}

Anxiety is described as a universal and negative emotion (Simpson, Neria, LewisFernandez, \& Schneier, 2010). In the fifth edition of the Diagnostic and Statistical Manual of Mental Disorders (DSM-5) anxiety is classified as a response to the expectation of a future threat (American Psychiatric Association; APA, 2013). Anxiety disorders, however, feature not only excessive levels of fear (the response to an immediate threat) but also excessive feelings of apprehension (APA, 2013). For a clinical diagnosis of an anxiety disorder, an individual must meet criteria specific to one of the ten different types of anxiety disorders (APA, 2013). Each anxiety disorder also requires that the individual's fear and anxiety is developmentally inappropriate, persistent, significantly impacting on their functioning and that it cannot be attributed to another mental disorder or medical condition (APA, 2013).

Anxiety not only has debilitating effects on the suffering individual but also places a significant economic burden on society (Adler Nevo et al., 2014). Bodden, Dirksen, et al. (2008) report that anxiety disorders have the highest financial burden of all psychological disorders, costing the United States 47 billion dollars per annum. Anxiety disorders are not only highly prevalent in the United States, but also in Australia. The most recent Australian Bureau of Statistics (ABS) data states that more than 14\% of all Australians have a current diagnosis of an anxiety disorder (ABS, 2016). Furthermore, anxiety disorders are also the second most prevalent psychological disorder amongst Australian children, with one in seven children aged 4-17 years old experiencing an anxiety disorder in 2015 (ABS, 2016). These substantial 12-month prevalence rates are particularly alarming due to the numerous adverse outcomes in later life that have been associated with childhood anxiety disorders (Brendel \& Maynard, 2013). 
Brendel and Maynard (2013) note that children who have been diagnosed with an anxiety disorder can suffer negative impacts in their social, educational and family spheres. Anxious children are also more susceptible to depression, substance abuse, and other anxiety disorders later in life. Additionally, anxiety disorders are one of the most comorbid mental disorder in Australia (Slade et al., 2009). Often comorbid with another anxiety disorder, childhood anxiety also has high comorbidity with Attention Deficit, Hyperactive Disorder (ADHD) and depression (Adler Nevo et al., 2014; James, James, Cowdrey, Soler \& Choke 2015). This has encouraged extensive research within both psychological and medical research.

\section{Cognitive Behavioural Therapy for Childhood Anxiety: A Case for Parental Inclusion}

A large body of research has considered the efficacy of Cognitive Behavioural Therapy (CBT) for the treatment of childhood anxiety with robust findings that CBT is an effective treatment resulting in clinically significant anxiety reductions in 50-80\% of children (Pereira et al., 2016; Podell et al., 2013). When used to treat a child, CBT detects and targets the child's problematic thoughts, schemas, beliefs, and expectations causing their maladaptive behaviours and cognitions which underlie their anxiety (Barrett, Rapee, \& Dadds, 1996; Dowell \& Ogles, 2010). A review of CBT for childhood anxiety by James et al. (2015) found that CBT helps the anxious child cope and understand their bodily reactions and thoughts through psychoeducation. According to James et al. (2015), the cognitive aspect of CBT uses mechanisms such as self-control, positive reinforcement, and self-monitoring to change the anxious child's cognitions and beliefs. Additionally, the behavioural aspect of CBT can involve the modeling of non-anxious and adaptive behaviours as well as exposure therapy and relaxation training (James et al., 2015). These CBT techniques are based on the theory that anxiety is a learned response that can be unlearned or overridden (James et al., 2015). However, CBT is not uniformly effective and approximately $25-50 \%$ of CBT treated 
children do not see clinically significant improvements in their anxiety following treatment (Kendall et al., 1997). This has encouraged further research into the potential moderators of the child's anxiety outcome following treatment.

One such moderator that has received considerable attention in the literature is parental involvement in therapy (Pereira et al., 2016). By exploring the literature surrounding the development and maintenance of childhood anxiety, it can be seen why including parents in their children's anxiety treatment could be beneficial for the child. Research into the aetiology of childhood anxiety has proposed several theoretical frameworks that explore the parental influence in the development and maintenance of childhood anxiety (Barrett, 1998; Brendel \& Maynard, 2013; Matthewson, Burton-Smith \& Montgomery, 2012). According to learning theory, childhood anxiety can be learned and maintained through modelling, reinforcement, and punishment from that child's significant others - their parents (Matthewson, 2009). Specifically, childhood anxiety may develop and be maintained directly or vicariously through their parents own actions and behaviours. Additionally, attachment theory poses that for a child to have healthy emotional development they must also develop and maintain a healthy and secure attachment to their parents (Bowlby, 1988). This secure attachment provides children with a safe base from which the child can explore their world, learn and develop new and adaptive relationships (Bowlby, 1988).

Studies have also found that parental factors such as modeling, encouragement, overprotection, emotions, attachment, control, support and parental psychopathology can all be associated with child anxiety (e.g., Bogels, \& Phares, 2008). Verhoeven, Bogels, and van der Bruggen (2012) state that parental overcontrol and parental autonomy granting are the most important of these parental factors associated with childhood anxiety. 


\section{Existing Literature and the Child-Only vs. Parental Inclusion Debate}

Previous literature exploring the influences of parental inclusion on their child’s anxiety has predominantly focused on the maternal influence (Verhoeven et al., 2012). Parke (2004) note that fathers are often the forgotten parents within this literature and that parenting is typically synonymous with mothering. However, some research has shown that modern fathers are unique contributors to their child’s rearing and family (Bogels, \& Phares, 2008). Additionally, Parke (2004) believes the traditional paternal role has shifted making fathers important contributors to their children’s social-emotional development. For example, Bogels and Phares (2008) found that fathers provide preadolescents with support and security when exploring their independence, the social world and as they begin to take risks. It is at this stage of development that mothers need to reduce their control of the child in order to facilitate adaptive development and prevent anxiety (Bogels \& Phares, 2008). This research and literature provides justification to not only include both mothers and fathers in research into the treatment of childhood anxiety but also highlights the unique and important paternal role especially during preadolescence or middle childhood (ages 6-12 years; Bornstein, 2002).

Yap and Jorm (2015) also advise that including parents in psychological treatment is a good approach to treatment as it is the parents who have the experience, foresight, and motivation required for successful treatment that children often lack. Brendel and Maynard (2013) also note that including parents in treatment may be the ideal way to enable the successful transmission of therapy skills from the clinician's office into the child's daily routine and home environment. Furthermore, it is the parents who can alter this home environment and provide access to these treatments (Yap \& Jorm, 2015). 
Several child anxiety studies have examined if indeed parental involvement in therapy results in improvements such as reduced anxiety symptoms for the anxious child (Aydin, 2014). For this review, PCBT will refer to any CBT based intervention which has an element of parental involvement, while ICBT will refer to a CBT based intervention that involves only the anxious child and has no or minimal parental involvement. While the exact therapy used in each study varies, both PCBT and ICBT involve using CBT to treat the anxious child. Additionally, both PCBT or ICBT may be a group or individually based interventions. In PCBT both the anxious child and their parents receive CBT. The parental component to PCBT aims to modify the parents' beliefs and expectations about their anxious child and educate them about how to appropriately model adaptive behaviours for their child (James et al., 2015). Furthermore, within some studies, the PCBT may also be used to treat the parents own anxiety and not just their child's (James et al., 2015). For children, CBT is typically only practical from age six or once a sufficient level of cognitive development has occurred (James et al., 2015). Thus, below this, it is common for only parents are included in the child's CBT. However, it has remained unclear if parents should remain involved after the age of six years (Middle childhood; James et al., 2015).

One such study which tested the differential effects of parental involvement in therapy is the meta-analysis by Dowell and Ogles (2010). This meta-analysis included forty-eight studies that compared child only psychotherapy to psychotherapy which included both the child and their parents on the child's psychotherapy outcome. While not specifically focused on childhood anxiety or CBT the results of this meta-analysis suggest parental involvement resulted in moderate ( $\mathrm{d}=0.27$ ) advantages over child only therapies and concluded that parents should be included in the psychotherapeutic treatment of children (Dowell \& Ogles, 2010). This study is particularly relevant as the mean age of children included in the Dowell and Ogles (2010) meta-analysis was 12 years of age $(S D=3.30)$. 
Another systematic review and meta-analysis conducted by Brendel and Maynard (2013) compared the effects of PCBT to the effects of ICBT on anxiety outcomes for children with anxiety disorders. Including eight studies with a total of 710 participants between the ages of 6-17 years, this meta-analysis showed that all of the included studies found PCBT and ICBT to be effective treatments for childhood anxiety. Only one; Wood, Piacentini, SouthamGerow, Chu, and Sigman (2006), found a statistically significant difference in treatment conditions. This difference meant that PCBT had a significant $(\mathrm{p}<.0 .05)$ advantage and resulted in more improved anxiety outcomes (OR=.88, 95\% CI [0.22, 1.53]) than ICBT (Wood et al., 2006). While, Wood et al. (2006) was the only study to have significant findings at the individual study level, upon conducting a meta-analysis Brendel and Maynard (2013) also found a significant summary effect. This small and significant effect showed that PCBT was more efficacious than ICBT (OR=0.26, 95\% CI [0.05, 0.47], $\mathrm{p}=<.05$ ).

Subsequently, Brendel and Maynard (2013) concluded that PCBT appears to be the more efficacious treatment for childhood anxiety when compared to ICBT.

Furthermore, upon meta-analyses Manassis et al. (2014) found that this advantage of parental involvement in therapy was moderated by the amount and quality of the parents' involvement. This study, however, focused on the level of parental involvement with three conditions; (1) low involvement, (2) active involvement with an emphasis on the moderators of contingency management (CM) and transfer of control (TC) and (3) active involvement without CM and TC emphasis. Their results suggested that CBT with active parental involvement and no emphasis on CM and TC was less effective than the low parental involvement condition. Additionally, Manassis et al. (2014) found that active parental involvement with CM and TC emphases had a delayed effect, with a significantly lower rate of anxiety one-year after treatment compared to the rates of anxiety immediately posttreatment. This delayed effect was not found for the low parental involvement or parental 
involvement without CM and TC emphasis. These findings by Manassis et al. (2014) suggest that active parental involvement in childhood anxiety treatment can lead to significant advantages over treatment that involves the child only but that this was further moderated by the level and quality of parental involvement. Moreover, these results also suggest that there is possibly a delayed effect of this active parental involvement when CM and TC are emphasised.

Conversely, some studies into parental inclusion have found an advantage for ICBT over PCBT. For example, a study by Bodden, Bogels et al. (2008), which compared the effectiveness of ICBT and PCBT for childhood anxiety, found that the ICBT condition was significantly more effective than the PCBT condition. Bodden, Dirksen, et al. (2008) also showed that this advantage found in Bodden, Bogels et al. (2008) for an ICBT advantage over PCBT was not just for treatment effectiveness but also cost-effectiveness, with ICBT being significantly more affordable than PCBT. Cost-effectiveness is also an important consideration for this research. If only a small advantage effect for either treatment condition is found then this effect may be outweighed by the difference in cost for the treatment (Bodden, Dirksen et al., 2008).

In further addition to these already opposing findings, no significant advantage of active parental involvement has also been found in a study by Silverman, Kurtines, Jaccard, and Pina (2009). Comparing CBT for child anxiety with minimal parental involvement to one with active parental involvement, Silverman et al. (2009) found both treatment conditions to be similarly effective in reducing anxiety in the anxious child. Likewise, studies by Barrett, Duffy, Dadds and Rapee (2001), Siqueland, Rynn and Diamond (2005), and Cobham, Dadds and Spence (1998) whom all compare forms of PCBT to ICBT for childhood anxiety also found no significant differences in treatment effectiveness. Additionally, a study by Nauta, Scholing, Emmelkamp, and Minderaa (2003) found no value in adding a parenting training 
program to an ICBT condition despite the PCBT condition having extra time in treatment (Jongerden \& Bogels, 2015).

Despite numerous experimental studies, it is still not clear whether parental inclusion in CBT treatments for childhood anxiety results in significant positive advantages for that child's anxiety outcomes (Jongerden \& Bogels, 2015). Moreover, many of the studies synonymise parental inclusion with maternal involvement (Brendel \& Maynard, 2013;

Silverman et al., 2009), ignoring the unique paternal influence. Furthermore, other studies did not specify the proportion of mothers and fathers in their parental participants (Barrett et al. 2001; Manassis et al., 2014). Podell and Kendall (2011) recognise this maternal focus in research as an issue. Furthermore, they note that conclusions differ vastly depending on the outcome measure used to assess anxiety outcome. Pereira et al. (2016) highlight that these variances across study findings are likely due to methodological issues with the individual studies samples and anxiety measures.

\section{Advantages of Systematic Reviews and Meta-Analyses}

A meta-analysis is a data analysis technique that can synthesise the different evidence and effects from multiple studies so that the validity of their results can be enhanced, and they can be utilised to support both existing and new policy or practice (Borenstein, Hedges, Higgins, and Rothstein, 2011). The meta-analysis technique has the advantage of increasing measurement precision through including larger and more diverse samples from across numerous studies (Hanji, 2017). Additionally, a systematic review can reduce bias in results by detailing each of the included studies' characteristics including their methodological strengths and weaknesses (Hanji, 2017). When combined, a systematic review and metaanalysis can evaluate and synthesise numerous empirical results, allowing not only a more 
unbiased review of the existing literature but also a possible resolution and some clarity to the uncertainties and controversies surrounding a specific research area (Hanji, 2017).

\section{Rationale and Aims}

Due to the unclear findings in the previous literature, further research should be conducted into the effects and advantages that including parents in treatment has on their child's anxiety outcomes. According to Wei and Kendall (2014), these studies into family and parent based treatments are intended to increase parental involvement in their child's treatment. However, the exclusion of fathers in childhood anxiety research is undermining this intention (Hudson \& Rapee, 2001). Furthermore, Hudson and Rapee (2001) note that fathers should be an important focus of future research. Subsequently, the current study aimed to address this area of research.

As per the Preferred Reporting Items for Systematic Reviews and Meta-Analyses (PRISMA; Moher et al., 2009), the current study did not have explicit hypotheses, but rather a research question and objectives. The current systematic review and meta-analyses aimed to examine if, on the balance of evidence, including both mothers and fathers in a CBT based treatment of childhood anxiety (PCBT) would be more effective in reducing child anxiety than child individual or group CBT without any mother or father involvement (ICBT). The present systematic review and meta-analyses intended to eliminate a void in the literature, which failed to overtly include and/or mention fathers in the literature despite research showing that the role of fathers is unique in children's social-emotional development. 


\section{Method}

\section{Design}

The current study conducted a systematic review of the literature and two metaanalyses which followed both the PRISMA (Moher et al., 2009) checklist and the Cochrane Handbook of Systematic Reviews of Interventions guidelines (Cochrane Guidelines; Higgins \& Green, 2011). These guidelines reinforced the validity of the current study’s findings and ensured a detailed and reproducible methodology was achieved. Please see Appendix A for the PRISMA guideline checklist which has the corresponding page numbers for the present report.

\section{Procedure and Search Strategy}

A literature search of five databases was conducted between the $5^{\text {th }}$ and $10^{\text {th }}$ of May 2017, these databases included; The Web of science, PubMed, Embase, The Cochrane Library and PsychINFO. These databases were selected based on their broad coverage of relevant journals and ability to provide an adequate reflection of the existing literature. This search, while not exhaustive, was the most extensive that was achievable within the current study’s time frame. All searches used the following or similar terms: (family OR parent-child OR child-parent OR [mother AND Father AND Child]) AND (intervention OR therapy* OR treatment OR training) AND (child* and anxi*) AND (cognitive behavior* OR CBT). These search terms were trialed and reviewed to ensure they were targeted enough to limit results to only relevant literature without being specific about variations in key terms. Additionally, Medical Subject Headings (MeSH) terms and Subject Heading terms were used when available. Searches did vary slightly across databases due to their search capabilities. Full details of the search terms used within each database can be found in Appendix B. 


\section{Study Inclusion Criteria}

For inclusion in the current systematic review and meta-analysis literature needed to meet the following criteria: (a) had to be peer-reviewed journal articles; (b) originally published in English; (c) of randomised control trial, or quasi-experimental type design; (d) compared a child only CBT intervention for childhood anxiety (ICBT) to a CBT intervention for the anxious child AND both their parents OR a CBT intervention for the child along with some form of separate parent training or education for both the parents (PCBT); (e) the study must have included as many mothers and fathers as possible and stated the proportion of mothers and fathers who participated in the study; (f) child participants must have had a diagnosed DSM-IV, DSM-5 or ICD-10 anxiety disorder, or subclinical anxiety symptoms; (g) the mean age of the participating anxious children must have been between 7 and 13 years; (h) anxiety-based outcome data must have been collected for the child participants; (i) the children participating could not have a primary diagnosis of a different mental health disorder (e.g. depression), neurodevelopmental disorder (e.g. autism spectrum disorder) or medical condition (e.g. cancer). For more details of the search and selection process see Figure 1. 


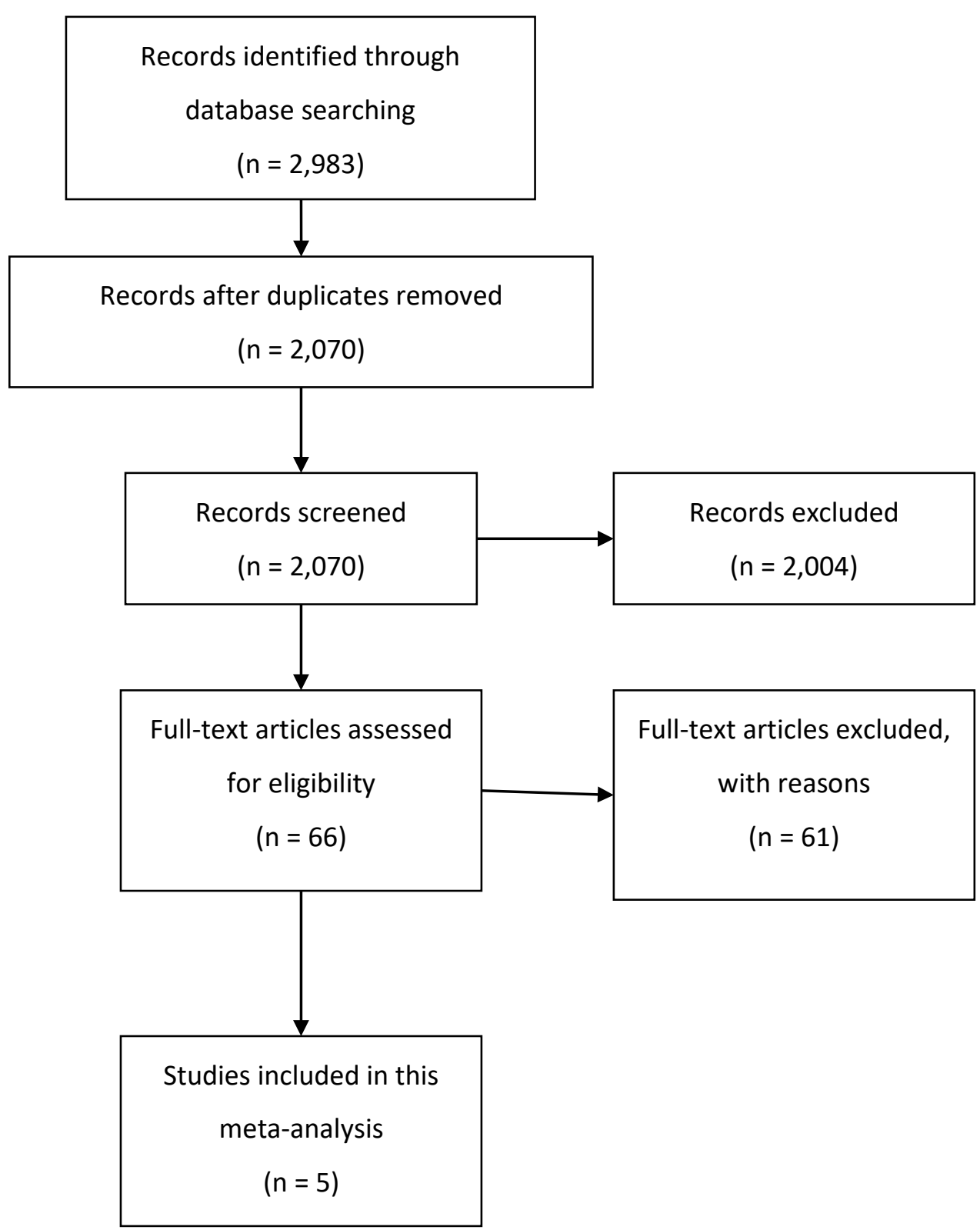

Figure 1. PRISMA (Moher et al., 2009) flow diagram depicting the literature search and selection process for the current systematic review and meta-analysis. 


\section{Data Extraction}

Data was extracted for each of the included articles by the author using the same data extraction form for each article (see Appendix C). Information pertaining to the design, participants, purpose, specific interventions, methodology, measures, and results was extracted from the included articles and recorded on the extraction form. Data pertaining to the number of children and parent participants was in both basic count (Bodden, Bogels et al., 2008; Bodden, Dirksen et al., 2008; and Schneider et al., 2013) and percentage forms (Kendall, Hudson, Gosch, Flannery-Schroeder \& Suveg e, 2008; Marin, 2011; Simon, Bogels, \& Voncken, 2011). All participant data presented as a percentage was converted to basic count form with partial numbers being rounded to the nearest whole number. P. Kendall (Kendall et al., 2008), C. Marin (Marin et al., 2011) and E. Simon (Simon et al., 2011) were contacted using the email address provided in their respective articles to confirm the converted participant counts. P. Kendall replied that he would not be able to respond to the request in the near future and instead provided three relevant articles that he believed would be helpful. No reply was received from C. Marin by the completion of this study, and E. Simon's email was returned with an undeliverable notice. E. Simon was then subsequently contacted via her ResearchGate profile. She responded but was unable to answer the author's questions at that time. D. Bodden was contacted regarding the sample used in both Bodden, Bogels et al. (2008) and Bodden, Dirksen et al. (2008) and in her reply noted that both articles employed the same samples. Following this Bodden, Bogels et al. (2008) was excluded from the current study. As sufficient detail was given in the study to conduct the present meta-analyses Schneider et al. (2011) were not contacted for any additional information. 


\section{Assessment of Risk of Bias in the Included Studies}

To assess the included studies’ methodological quality and the risk of their quality biasing the current studies results, the current study employed the risk of bias tool from the fifth version of the Cochrane Collaboration’s Review Manager program (RevMan5; Cochrane Collaboration, 2014). This tool uses a domain-based evaluation where critical assessments are made across seven domains. These seven domains are based upon six types of biases: selection bias, performance bias, detection bias, attrition bias, reporting bias and other biases. The seven domains are known as ‘sequence generation', 'allocation concealment', 'blinding of participants and personnel', 'blinding of outcome assessment', 'incomplete outcome data', 'selective outcome reporting', and 'other potential threats'. This tool requires authors to evaluate each study and assign and justify an assessment of risk level ('Low risk', 'High risk', 'Unclear risk', of bias) to each one of these domains (for more information see the Cochrane's Handbook, Higgins \& Green, 2011). Following this, a summary of bias table or graph can be generated within RevMan5 (Cochrane Collaboration, 2014). The current study includes a summary of bias table for each meta-analysis in the respective figures (see figure 2 and figure 3) as well as a risk of bias graph in Appendix D. The justification for the current studies assessments of the included studies' risk of biases and how this influences the present analyses will be discussed in the results section.

\section{Data Analysis}

All analyses were conducted using the Cochrane Collaborations Review Manager program (RevMan5; 2014). This software was selected due to the current study's adoption of the Cochrane Guidelines (Cochrane Guidelines; Higgins \& Green, 2011), the software's ability to both analyse data and publication bias and its easy-to-use interface. Three separate analyses were conducted; including two separate meta-analyses of time-points and one 
subgroup analysis comparing these time-point analyses for evidence of a significant difference in effect across time-points.

\section{Time-point measures.}

Based on a review of the included articles two common time-points were used to measure the anxious child's anxiety data; immediately post-treatment and a one-year posttreatment follow-up. It should also be noted here that not all the included studies measured at both time-points. Bodden, Dirksen, et al. (2008), Kendall et al. (2008), Schneider et al. (2013) all measured immediately (within a month) post-treatment and at a one-year post-treatment follow-up. However, Marin (2011) only measured at the immediately post-treatment timepoint, while Simon et al. (2011) only measured at the one-year post-treatment time-point. These common time-points informed the current study's decision to conduct two separate meta-analyses; analysis one: immediately post-treatment and analysis two: one-year posttreatment follow-up. Analysis one calculated individual effects for the immediately posttreatment data for Bodden, Dirksen et al. (2008), Kendall et al. (2008), Marin (2011) and Schneider et al. (2013) before combining these effects for a test of the heterogeneity across studies and an overall test of effect. This analysis was then repeated for analysis two which assessed for an overall treatment effect with the one-year post-treatment follow-up data and the individual study effects of Bodden, Dirksen et al. (2008), Kendall et al. (2008), Schneider et al. (2013) and Simon et al. (2011). Subsequently, a subgroup analysis comparing the overall effects from these individual analyses was also conducted to evaluate if there was a significant difference in treatment effect between time-point analyses. 


\section{Anxiety-based outcome data.}

Upon a further review of the included articles, the current study conducted both the time-point meta-analyses using dichotomous diagnostic data (free from anxiety or not) for the anxious child. In all the included studies childhood anxiety based outcome data was measured using a version of the Anxiety Disorders Interview Schedule (ADIS; Silverman \& Albano, 1996) except for Schneider et al. (2013). Schneider et al. (2013) instead used the child and parent versions of the Diagnostic Interview for Children and Youth for the DSM-IV-TR (Kinder-DIPS; Schneider, Unendear, \& Margraf, 2009). Both measures produce proportion based dichotomous data for the number of anxiety-free children. However, it should be noted that not all studies classified children as anxiety free in the same way. Simon et al. (2011) used an "ADIS Improved” criterion, which stated children were “ADIS Improved” if there was an effect size change of $d=0.5$ or higher between pre-treatment and follow-up. Additionally, Marin (2011) only required children to be free from their primary anxiety diagnosis. While, Kendall et al. (2008), Bodden, Dirksen et al. (2008) and Schneider et al. (2013) all classified children as entirely free from an anxiety diagnosis. While this dichotomous diagnostic data was not the only measurement employed within the included studies, it was the only common variable measured across all the studies. Therefore, the current meta-analyses were computed using each study's basic count data for the number of children who were anxiety free at each time-point for each treatment condition (PCBT and ICBT). For studies reporting percentages, basic count data was computed to the nearest whole number. 


\section{Effect size measure.}

Odds ratio based effect size measures with 95\% confidence intervals were calculated using RevMan5 (Cochrane Collaboration, 2014) for each study and the overall summary effect. Odds ratios were selected due to the dichotomous nature of the data and the independence between the PCBT and ICBT treatment groups. Odds ratio are explained by Borenstein et al. (2011) as being the ratio between the two odds: first the odds of the target event occurring (being anxiety free) and second the odds of the target event not occurring (continuing to have anxiety). The odds of the target event occurring (Odds) are calculated for each treatment condition (PCBT and ICBT) by:

$$
\text { Odds }=\frac{A}{B}
$$

where the number of events that occurred is denoted by $A$ and the number of events not occurring is denoted by $B$.

Following this, the odds ratio of the target event occurring is calculated by:

$$
\text { OddsRatio }=\frac{O d d s_{A}}{O d d s_{B}}
$$

\section{Meta-analytic method.}

The current study's two meta-analyses both employed the random effects model which allows the true effect being analysed to vary between studies (Borenstein et al., 2011). This means the model appreciates the true underlying effect could be unique to each study that is included due to the subtle differences between each study. Differences included the studies' participants' mean age, the proportions of mother and fathers and any sampling error (Borenstein et al., 2011). Borenstein et al. (2011) argue that this model is superior to the alternative fixed-effects model (which assumes there is only one true effect underlying all the studies included in the analysis) as the random effects model can calculate and account the between-study heterogeneity in the final meta-analysis. 
Within RevMan5 two random effects methods can be used to analyse dichotomous data: The Mantel-Haenszel method ( $\mathrm{MH})$ and the inverse-variance method (Higgins and Green, 2011). For the current meta-analyses, the MH random effects model was employed which estimates the amount of between-study variance by comparing each study's result with a MH fixed effect meta-analysis result. Hanji (2017) notes that the MH method of pooling the individual effects from each study is robust and preferable when sample sizes are small, and event rates are low as was the case with the current data. For the meta-analyses, each study's effect size $\theta_{i}$ was weighted $w_{i}$ according to the number of participants. Following this, the overall estimate of the pooled effect $\theta_{i}$ was estimated by

$$
\theta_{M H}=\frac{\sum w_{i} \theta_{i}}{\sum w_{i}}
$$

\section{Assessment of heterogeneity.}

To assess the heterogeneity across the included studies, the current study employed three measures of heterogeneity; Tau-squared, Cochran's Q, and the $I^{2}$ statistic. Tau-squared is defined by Borenstein et al. (2011) as the variance of the true effect size which has been estimated from the observed effects and denoted as $\mathrm{Tau}^{2}$ and is in the same metric (squared) as the effect size in use (Odds ratio). Tau ${ }^{2}$ reflects the total variance in the scale of the effect and can never be less than zero unless sampling error has occurred. Tau ${ }^{2}$ is computed by:

$$
\mathrm{Tau}^{2}=\frac{\mathrm{Q}-d f}{\mathrm{C}}
$$

where $\mathrm{Q}$ is Cochran's $\mathrm{Q}$ (discussed in more detail further on), $d f$ is degrees of freedom and $C$ puts $\mathrm{Tau}^{2}$ back into its odds ratio metric and makes it an average of squared deviations is calculated by:

$$
C=\sum w_{i}-\frac{\sum w_{i}^{2}}{\sum w_{i}}
$$


Cochran's Q is also commonly used to assess heterogeneity and can be computed by summing the weighted squared deviations of each study’s effect size estimates (Higgins, Thompson, Deeks, \& Altman, 2003). P values of this statistic are then obtained by comparing the $\mathrm{Q}$ statistic with a chi-square $\left(\chi^{2}\right)$ distribution with $\mathrm{k}-1 \mathrm{df}$ (where $\mathrm{k}$ is the number of studies; Higgins et al., 2003). With a significant p-value for this $\chi^{2}$ distribution indicating heterogeneity across the included studies (Higgins et al., 2003).

The $\mathrm{I}^{2}$ statistic was also employed in the current study as a measure of heterogeneity as this measure unlike $\mathrm{Tau}^{2}$, and the $\mathrm{Q}$ statistic is independent of the scale and number of studies included (Borenstein et al., 2011). The $\mathrm{I}^{2}$ statistic is a percentage based measure which describes the total variation across studies that is due to heterogeneity and not chance (Higgins et al., 2003). Values are between $0 \%$ and $100 \%$, with values of $\leq 25 \%$ indicating low heterogeneity, values around 50\% indicating high heterogeneity and values $\geq 75 \%$ indicating high heterogeneity (Higgin et al., 2003). $\mathrm{I}^{2}$ is calculated as:

$$
I^{2}=\frac{100 \% \times(\mathrm{Q}-d f)}{\mathrm{Q}}
$$




\section{Results}

\section{Systematic Review of the Literature}

The initial search returned a total of 2,983 records, 913 of these were duplicates and subsequently were excluded. For the first screen, the remaining 2,070 records had their titles and abstracts screened by the author for relevance. As a result of this first screen, 2,004 records were excluded for not meeting the current studies inclusion criteria. The full-text articles were then retrieved for the remaining 66 records and further assessed against the inclusion criteria. Following this, 61 of these articles were excluded with reason; these reasons include, not comparing PCBT and ICBT interventions, not including both mothers and fathers, not including the numbers of mother and father participants, or not having a randomised control trial or quasi-experimental design. In total, six separate articles (Bodden, Bogels et al., 2008; Bodden, Dirksen, et al., 2008; Kendall et al., 2008; Marin, 2011; Simon et al., 2011; Schneider et al., 2013) met the current studies full inclusion criteria. However, one of these articles (Bodden, Bogels et al., 2008) was later excluded after contacting the author for further details regarding the participant sample. Upon contacting D. Bodden (the contact author listed for both Bodden, Bogels, et al., 2008 and Bodden, Dirksen et al., 2008), it became apparent that both studies used the same sample of participants. Following this, the current study reviewed both studies and it was decided that only Bodden, Dirksen et al. (2008) would be included as this was the only study of the two that analysed the childhood anxiety data at both an immediately post-treatment and one-year post-treatment follow-up time-point. Subsequently, five studies were included in the current review and meta-analyses (Bodden, Dirksen et al., 2008; Kendall et al., 2008; Marin, 2011; Simon et al., 2011; Schneider et al., 2013; for a summary see Table 1). 
Table 1

Summary of Reviewed Articles

\begin{tabular}{|c|c|c|c|c|c|c|}
\hline $\begin{array}{c}\text { Author } \\
\text { (year) }\end{array}$ & $\begin{array}{l}\text { Study } \\
\text { Design }\end{array}$ & Participants & Purpose & Intervention/Methodology & Measures & Results \\
\hline $\begin{array}{l}\text { Bodden, } \\
\text { Dirksen et } \\
\text { al. (2008) }\end{array}$ & $\begin{array}{l}\text { Multi- } \\
\text { center } \\
\text { RCT }\end{array}$ & $\begin{array}{l}116 \text { children ( } 72 \\
\text { Females, } 98 \% \\
\text { Caucasian) aged 8- } \\
\text { 17yrs } \\
\text { (M=12.30yrs) } \\
\text { diagnosed with a } \\
\text { primary anxiety } \\
\text { disorder other than } \\
\text { OCD or PTSD. } \\
\text { 95\% of Fathers } \\
\text { and } 99 \% \text { of } \\
\text { Mothers } \\
\text { participated. }\end{array}$ & $\begin{array}{l}\text { To compare the } \\
\text { costs and } \\
\text { effectiveness of } \\
\text { PCBT and ICBT } \\
\text { for childhood } \\
\text { anxiety. A follow- } \\
\text { up study to Bodden, } \\
\text { Bogels, et al., 2008. }\end{array}$ & $\begin{array}{l}\text { Following pre-treatment measures, } \\
\text { participants were randomly assigned } \\
\text { to } 12,60-90 \text { min sessions of either } \\
\text { PCBT ( } 57 \text { families) or ICBT ( } 59 \\
\text { children). PCBT consisted of } \\
\text { varying combinations of family } \\
\text { members at each session. } \\
\text { Immediately following the } \\
\text { intervention participants completed } \\
\text { post-treatment measures. These } \\
\text { measures were then repeated at 3- } \\
\text { and } 12-\text { months post-treatment time- } \\
\text { points. }\end{array}$ & $\begin{array}{l}\text { ADIS-Child \& } \\
\text { Parent version, } \\
\text { ADIS-Adult } \\
\text { version, } \\
\text { EuroQol-5D, } \\
\text { Cost Diary, and } \\
\text { Questionnaires } \\
\text { of Anxiety, } \\
\text { Psychopatholog } \\
\text { y, Cognition, } \\
\text { Rearing and } \\
\text { Family } \\
\text { Functioning. }\end{array}$ & $\begin{array}{l}\text { No significant differences between } \\
\text { PCBT and ICBT on cost- } \\
\text { effectiveness were found at any of } \\
\text { the time-points. }\end{array}$ \\
\hline $\begin{array}{l}\text { Kendall et } \\
\text { al. (2008) }\end{array}$ & RCT & $\begin{array}{l}161 \text { ( } 71 \text { Females, } \\
85 \% \text { Caucasian) } \\
\text { children aged } 7- \\
14 y r s(\mathrm{M}=10.27 \mathrm{yrs} \\
\text { ) and diagnosed } \\
\text { with a principal } \\
\text { anxiety disorder. } \\
80 \% \text { of Fathers } \\
\text { and } 100 \% \text { of }\end{array}$ & $\begin{array}{l}\text { To evaluate the } \\
\text { efficacy of PCBT } \\
\text { and ICBT in } \\
\text { comparison to } \\
\text { FESA (Family- } \\
\text { based Education, } \\
\text { Support, and } \\
\text { Attention) an active } \\
\text { comparison } \\
\text { treatment for child } \\
\text { anxiety. }\end{array}$ & $\begin{array}{l}\text { Following screening and pre- } \\
\text { treatment measures participants } \\
\text { were randomly assigned to one of } \\
\text { the three interventions: PCBT ( } 56 \\
\text { families), ICBT ( } 55 \text { children) or } \\
\text { FESA ( } 50 \text { families), all of which } \\
\text { consisted of 16, one-hour-long, } \\
\text { weekly sessions. Immediately post- } \\
\text { treatment and after one-year post- } \\
\text { treatment participants completed } \\
\text { several measures. }\end{array}$ & $\begin{array}{l}\text { ADIS-Child \& } \\
\text { Parent versions, } \\
\text { MASC, CQ-C, } \\
\text { CBCL, TRF, } \\
\text { CQ-P, and } \\
\text { CPTR. }\end{array}$ & $\begin{array}{l}\text { Children showed treatment gains } \\
\text { across all three interventions, but } \\
\text { PCBT and ICBT reduced the } \\
\text { presence and principality of the } \\
\text { child's anxiety disorder more than } \\
\text { FESA. ICBT also outperformed } \\
\text { PCBT and FESA on teacher reports } \\
\text { of child anxiety. These treatment } \\
\text { gains were maintained at the one- } \\
\text { year follow-up time-point. } \\
\text { Additionally, when both parents had }\end{array}$ \\
\hline
\end{tabular}


Table 1

Summary of Reviewed Articles

Mothers

participated.

Marin

RCT 183 children (85

(2011)

Females, $76 \%$
Hispanic/Latino)

Hispanic/Latino)

(M=9.72yrs) who

presented to the

Child Anxiety and

Phobia Program at

Florida

International

University.

$94 \%$ of Fathers

and $95 \%$ of

Mothers

participated.

Schneider RCT 64 children (33

et al.

(2013)
Females) aged 8-

$13 y r s$

( $M=10.36 y r s)$ who

met DSM criteria

for SAD and spoke

German.

An average of

$85 \%$ of fathers and

\section{A dissertation}

comparing PCBT

and ICBT with the

aim to examine

treatment

specificity and the

mediation effects of

including parents

and peers in CBT

for Child Anxiety.

To examine the

efficacy of a

family-based SAD

intervention

(PCBT) compared

to a general anxiety program (ICBT)
Along with the initial assessment interviews, all measures were

completed at pre-treatment.

Following this, participants were randomly assigned to PCBT (100 children), or ICBT (83 children) in which they participated in 12-14 therapy sessions. All pre-treatment measure was then repeated immediately post-treatment.
Before treatment began baseline measures and diagnostic interviews were conducted. Both PCBT and ICBT consisted of 16 therapy sessions that were 50mins long.

Participants were randomly assigned their treatment condition either PCBT (31 families) or ICBT (33 children). Immediately following treatment, at one month and one- an anxiety disorder PCBT outperformed ICBT. Parent versions for Child and Mother Only, CBCL, C-GAS, RCMAS and RCMAS Parent version, CBQ, CRPBI \&

PRPBI, FQ, and SSRS-Adult \&

Child versions.
ADIS-Child \&

Both PCBT and ICBT were equally effective treatments for childhood anxiety with anxiety reductions found across all measures of change.

There were no significant differences in the percentage of anxiety-free children using the ADIS data between PCBT and ICBT. Significant changes included recovery and symptom reduction as well as lower scores on both RCMAS and RCMAS/P. Some treatment specific effects were found for both PCBT and ICBT.

Kinder-DIPS, SAAI-Child \& Parent versions, GSR-

Child/Parent/Te acher versions, SDS, RCMAS, IQL-Child \& Parent versions, and the German
No significant differences between PCBT and ICBT at the immediately post-treatment or one-year follow-up time-points were found for any of the measures. Therefore, both PCBT and ICBT were equally efficacious treatments of child anxiety. 
Table 1

Summary of Reviewed Articles

\section{$100 \%$ of mothers participated across conditions.}

Simon et RCT

183 highly anxious children (100

Females) and 74 medially anxious children (34

Females, 98\% Dutch) aged 813yrs (M=9.92) were recruited through screening conducted at a primary school. $100 \%$ of Fathers and Mothers participated. year follow-up, post-treatment measures were administered. Not all participants completed all the measures at each time-point.

To examine the development of anxiety in medially and highly anxious children, the effect of preventative PCBT and ICBT interventions on parental and childhood anxiety, and the effect of parental anxiety on childhood anxiety.

\section{After initial screening using the} SCARED-71, highly anxious children (the top 15\%) were randomised into the PCBT (69 parental couples), ICBT (58 children), or no intervention group. Following the pre-test and PCBT and ICBT participants completed eight, 90min sessions in groups of 68 couples or children. At one-year and two-years post-treatment, follow-up measures were taken.

version of the

PBQAC.

ADIS-Child/ Parent/Dutch versions,

SCARED-71 Item, Revised, \& Adult versions.
Highly anxious or at-risk children were more susceptible to having or developing anxiety problems than median anxious children. Both PCBT and ICBT showed positive outcomes when compared to no intervention on the no. of ADIS improved children, but this advantage was not significant. However, at the two-year follow-up time-point, both PCBT and ICBT were equally and significantly advantaged over the no treatment condition. Meaning no advantage for PCBT o ICBT was found.

Note: ADIS= Anxiety Disorder Interview Schedule; MASC= Multidimensional Anxiety Scale for Children; CQ-C= Coping Questionnaire-Child; CBCL= Child Behaviour Checklist; TRF= Teacher Report Form; CQ-P= Coping Questionnaire-Parent; CPTR= Child's Perception of Therapeutic Relationship; C-GAS= Children's Global Assessment Scale; RCMAS= Revised Children's Manifest Anxiety Scale; CBQ= Conflict Behaviour Scale; CRPBI= Child Reported Parenting Behaviour Inventory; PRPBI= Parent-Reported Parenting Behaviour Inventory; FQ= Friendship Questionnaire; SSRS= Social Skills Rating System; Kinder-DIPS= Diagnostic Interview for Children and Youth for the DSM-IV-TR; SAAI= Separation Anxiety Avoidance Inventory for Children; GSR= Global Success Rating; SDS= The adapted Sheehan Disability Scale; IQL=Inventory for the Assessment of Quality of Life in Children and Adolescents; PBQAC= Parents’ Dysfunctional Cognitions About the Child and Parenting; SCARED-71= Screening for Anxiety Related Disorders. 
Within these five articles, there was a total of 707 child participants (M=10.51 years, $52 \%$ Female), and 686 or $97 \%$ of these were included within the present meta-analyses because they had the appropriate diagnostic anxiety data. Averaged across all five studies, $90.6 \%$ of the total number of anxious children's fathers were included and $98.8 \%$ of their mothers. All five studies conducted randomised control trials (RCT) with several studies being conducted out of European countries such as the Netherlands (Bodden, Bogels, et al., 2008; Simon et al., 2011) and Germany (Schneider et al., 2013). The remaining two did not clearly state their location (Marin, 2011 and Kendall et al. 2008). For a more detailed summary of the characteristics and results for each of the five included studies see Table 1.

\section{Summary of Bias}

Publication bias is the increased likelihood of a study being published due to it having significant results (Borenstein et al., 2011). This bias is an important consideration for metaanalyses as it has the potential to vastly influence the magnitude and direction of the underlying effect being examined (Borenstein et al., 2011). However, for the current metaanalysis publication bias was not identified as an issue due to the majority of the included studies not having found significant results in any of their analyses (see Table 1).

Upon assessing the risk of bias for each the individual studies, across the RevMan5's seven domains of bias (see Figure 2 and Figure 3 for risk of bias summary for each analysis) the present study found that all of the included literature was overall of high quality. All the included studies were assigned an evaluation of 'unclear risk' for the allocation concealment domain, which assesses selection bias. This was due to the nature of the treatment interventions being compared within these studies. It was not possible for the included studies to conceal the treatment conditions from their participants as it was overt from the presence of the child's parents in treatment, which participants were in the ICBT and PCBT conditions. Furthermore, Kendall et al. (2008), Schneider et al. (2013), and Simon et al. 
(2011), also received evaluations of 'unclear risk' for the selective reporting domain which assesses reporting bias (see Figure $2 \& 3$ ). This was due to an insufficient level of information about the studies pre-specified outcomes and the Cochrane Handbook notes that this evaluation is to be expected unless the study has cited that a study protocol was used (Higgins \& Green, 2011). One study, Kendall et al. (2008) was evaluated as having a 'high risk' of attrition bias based on the assessment of the incomplete outcome data domain. This evaluation was justified due to the unclear nature of the attrition between time-point measures as the numbers of children, mothers, and fathers being measured across conditions and times varied without explanation. No discussion of these variances was made within the study itself beyond a flow chart of participants, and furthermore, no response was received upon contacting the authors for further explanation. All other studies and domains not mentioned here received a 'low risk' of bias assessment. Despite the 'high risk' and 'unclear risk' of bias evaluations, the included study's risk of biases overall was very low, and it is likely that their results and estimation of their underlying effects are valid (for further detail see figures 2, 3 \& Appendix D).

\section{Overall Effectiveness of PCBT and ICBT for Childhood Anxiety}

Both PCBT and ICBT were found to be effective treatments at both the immediately post-treatment and one-year post-treatment time-point analyses. Respectively, PCBT and ICBT resulted in $63.35 \%$ and $60.49 \%$ of children being free from the presence of their principle anxiety disorder immediately post-treatment. Furthermore, at the one-year posttreatment time-point analysis these figures were $59.29 \%$ and $56.13 \%$ for PCBT and ICBT respectively. 


\section{Analysis One: Immediately Post-Treatment Meta-Analysis}

The immediately post-treatment meta-analysis of analysis one demonstrates a nonsignificant $(\mathrm{p}>0.05)$ advantage of ICBT over PCBT, with ICBT resulting in more children being anxiety free immediately post-treatment $(\mathrm{OR}=1.34[0.61,2.92], \mathrm{p}=0.46)$. For more information for this test of overall effect including individual study data, odds ratios, $95 \%$ confidence intervals, and weights see figure 2. The analysis of heterogeneity (see figure 2) demonstrated there is significant and moderate to large heterogeneity across the four studies included in analysis one $\left(\mathrm{Tau}^{2}=0.43 ; \chi^{2}=10.20, \mathrm{df}=3[\mathrm{p}=0.02] ; \mathrm{I}^{2}=71 \%\right)$. This suggests that the observed between-study variance is more than what would be expected from sampling error alone and likely due to differences in the underlying effects of each individual study. 
Analysis One: Immediately Post-Treatment Meta-Analysis

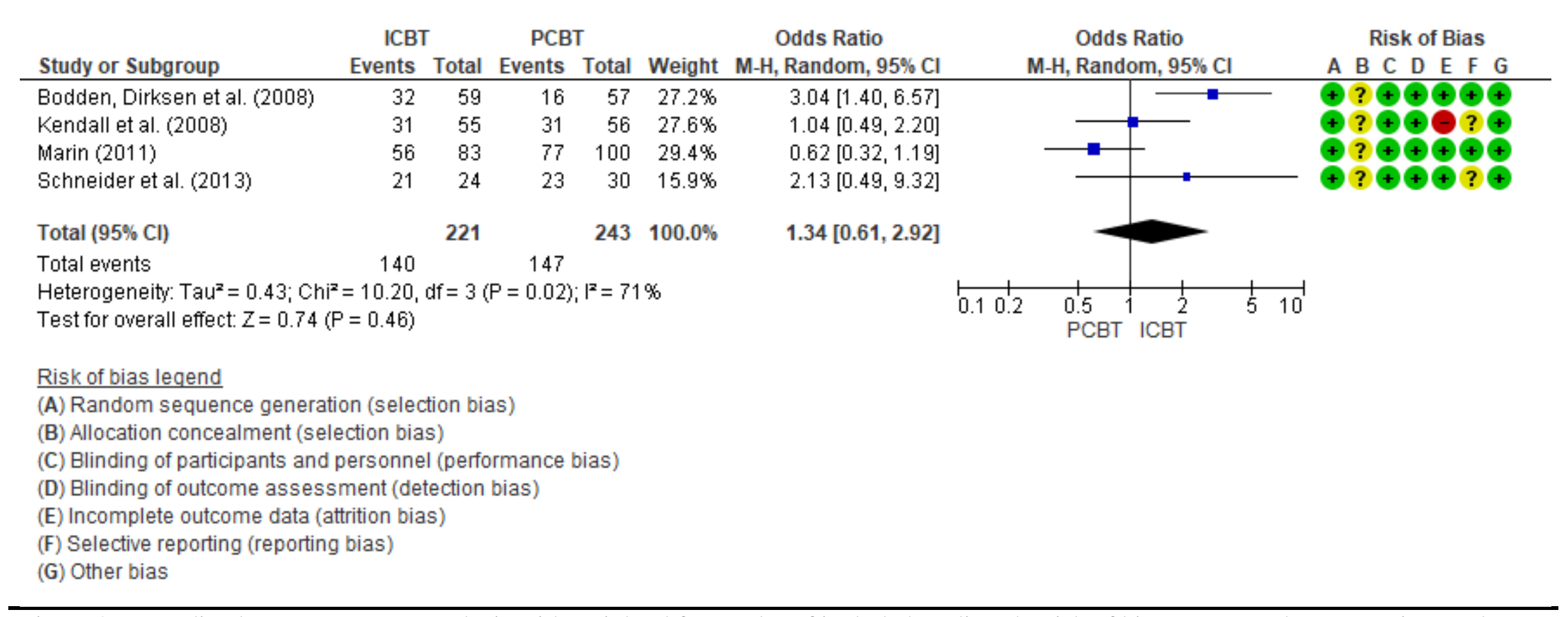

Figure 2. Immediately post-treatment analysis with weighted forest plot of included studies, the risk of bias summary, heterogeneity results and a test for overall effect using odds ratios, the Mantel-Haenszel method (M-H), a random effects model (Random) and 95\% confidence intervals (95\% CI). Where, odds ratios equal to 1 indicate no advantage, above 1 indicate an ICBT advantage, and below 1 indicate a PCBT advantage. 


\section{Analysis Two: One-Year Post-Treatment Follow-Up Meta-Analysis}

Similarly, the one-year post-treatment follow-up meta-analysis of analysis two demonstrates a non-significant ( $\mathrm{p}>0.05$ ) advantage of ICBT over PCBT, with ICBT continuing (from analysis one: immediately post-treatment) to result in more children being anxiety free at one-year post-treatment follow-up $(\mathrm{OR}=1.09[0.67,1.77], \mathrm{p}=0.74)$. For more information for this test of the overall effect, including the individual study data, odds ratios, 95\% confidence intervals, and study weightings see figure 3. The analysis of heterogeneity for analysis two (see figure 3) demonstrated a non-significant and low heterogeneity across the four studies included in analysis two $\left(\mathrm{Tau}^{2}=0.05 ; \chi^{2}=3.84, \mathrm{df}=3[\mathrm{p}=0.28] ; \mathrm{I}^{2}=22 \%\right)$. This suggests that the observed between-study variance is like due to sampling error alone. 
Analysis Two: One-Year Follow-up Meta-Analysis

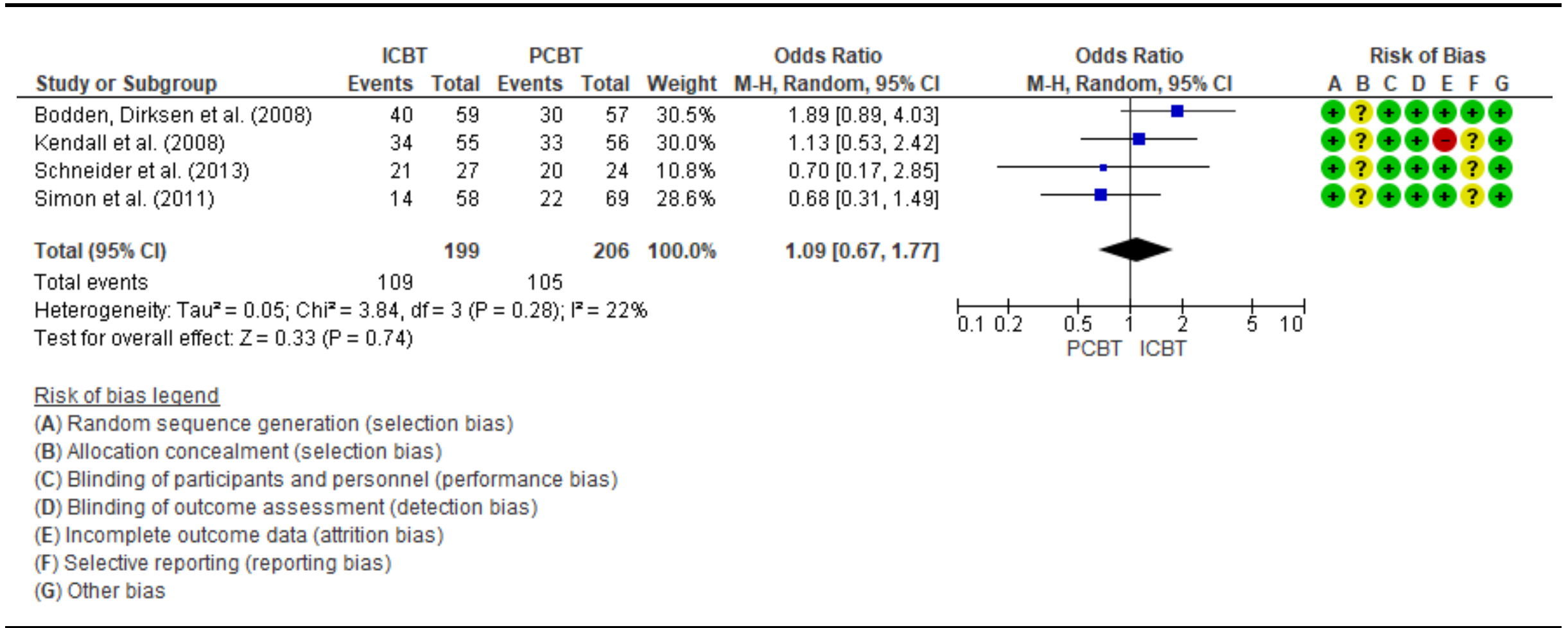

Figure 3. One-Year Follow-up analysis with weighted forest plot of included studies, the risk of bias summary, heterogeneity results and a test for overall effect using odds ratios, the Mantel-Haenszel method (M-H), a random effects model (Random) and 95\% confidence intervals

(95\% CI). Where, odds ratios equal to 1 indicate no advantage, above 1 indicate an ICBT advantage, and below 1 indicate a PCBT advantage. 


\section{Analysis Three: Time-Point Subgroup Analysis}

The subgroup analysis of the two time-points (analysis three) demonstrates a nonsignificant $(\mathrm{p}>0.05)$ difference between immediately post-treatment and one-year posttreatment follow-up time point analyses $\left(\chi^{2}=0.20, \mathrm{df}=1[\mathrm{p}=0.65] ; \mathrm{I}^{2}=0 \%\right)$. This result suggests no difference in effect from immediately post-treatment to one-year post-treatment for either ICBT or PCBT treatments on the diagnostic anxiety data.

\section{Discussion}

The present meta-analytic review aimed to examine if, on the balance of evidence including both mothers and fathers in PCBT for childhood anxiety would be more effective in reducing the anxious child's anxiety than ICBT with only children. Results from the analyses conducted here do not support an advantage for PCBT over ICBT for the treatment of childhood anxiety. Overall the present study did not find any support that the explicit inclusion of both mothers and fathers in PCBT results in significantly more positive treatment outcomes for anxious children than those obtained from including only the child in ICBT. Possible explanations for the current study's findings will be discussed and evaluated with reference to the existing literature. Furthermore, throughout this discussion, a critical evaluation of this existing literature together with the studies included in the present metaanalytic review will be given. Finally, any implications of the current study’s findings for future practice will be discussed before the final conclusions are presented.

\section{Summary of Findings}

\section{Literature review.}

A systematic search of five databases was conducted in May 2017, identifying almost 3000 records. Following several stages of screening, five of these records were classified as included based on the applied criteria. As both Bodden, Bogels et al., (2008) and Bodden, Dirksen et al., (2008) analysed the same sample data and did not specify this, it is suggested 
that future research is more explicit when samples may have been shared across studies. Additionally, it is also recommended that the authors for Bodden, Bogels et al. (2008) and Bodden, Dirksen et al. (2008) amend both of their reports to include a clear statement of the shared nature of the sample.

During the full-text screening process for the identified literature, a considerable number of studies that compared some form of PCBT to ICBT were identified. However, a majority of these studies only included or reported results for mothers. Some studies even exclusively focused on mothers despite purporting to use a parent or family-focused intervention and acknowledging the importance and uniqueness of fathers in their literature review (for example see Creswell \& Cartwright-Hatton, 2007). For other studies, there was limited mention and reporting of results for fathers and often the proportion of mothers and fathers included in the PCBT interventions was not explicitly stated (for example see Khanna \& Kendall, 2009). To prevent bias in the current meta-analytic review which had a focus on including both mothers and fathers, studies were excluded if they did not make a clear statement that the majority of mothers and fathers were included. However, this meant a considerable number of studies were excluded. Moreover, it is likely that had more detail been given regarding the mother and father participants in these studies then the current metaanalysis would have been able to include them thus making the current study much larger. Additionally, had there been more time the current study may have been able to contact more authors of potentially included studies to obtain this data. Future, meta-analyses should also consider contacting the authors of studies that have the potential for inclusion to seek the additional information required for inclusion. It is recommended that future research involving parents clearly articulates the number of mothers and fathers that are participating, regardless of the area of study. 
In the current study, an assessment of the methodological quality of the included studies was conducted to identify any possible biases that may undermine the present study's findings. This assessment identified that the current study's findings were at low risk of being biased by the included studies as they were all high quality (see Figure $2 \& 3$ and Appendix D).

\section{Efficacy of PCBT and ICBT.}

The present systematic review and meta-analyses combined data from the five included RCTs which all compared some form of PCBT with both mother and father involvement to child-only ICBT. Results from the first immediately post-treatment metaanalysis revealed that both PCBT and ICBT were efficacious treatments of childhood anxiety. It was found that both PCBT and ICBT resulted in over $60 \%$ of treated children recovering from their principle anxiety disorder immediately (within a month) post-treatment. Moreover, at the one-year post-treatment time-point analysis these figures were slightly less but not significantly different, and between 56-60\%.

These findings are consistent with previous literature showing that CBT is an efficacious treatment for childhood anxiety, resulting in remission rates of over 56\% (Cartwright-Hatton, Roberts, Chitsabesan, Fothergil, \& Harrington, 2004). Research indicates that clinical levels of childhood anxiety do not remit on their own; however, Hudson, Kendall, Coles, Robin, and Webb state that less severe anxiety may diminish over time without intervention. Furthermore, Cartwright-Hatton, et al., (2004) found a remission rate of $34.8 \%$ within their control group of children with anxiety. In the current study, only Simon et al. (2011) employed a control group, and consequently, the current meta-analytic review was not able to compare either treatment conditions to a baseline recovery rate in the sampled populations. Meaning, it is possible albeit, unlikely, that the recovery statistics found for the treatment conditions in the current meta-analyses were not significantly greater than no 
treatment. Thus, it is recommended that future research comparing PCBT to ICBT also include a control or waitlist condition to enable more comprehensive comparisons of treatment efficacy.

\section{Advantage of PCBT over ICBT.}

Upon meta-analyses of the treatment outcomes for PCBT and ICBT, no significant advantage for either treatment condition over the other for either time-points was found. Additionally, unlike the study by Manassis et al. (2014), the time-point comparison showed no evidence of parental inclusion having a delayed advantage (see Table 1). These results support those of Silverman et al. (2009), Barrett et al. (2001), Siqueland et al. (2005), and Cobham et al. (1998) whom all found no advantage of PCBT (without explicit inclusion of both parents) over ICBT. The current results in combination with these previous findings suggest that it is possible that PCBT, regardless of which parent is involved, provides no advantage for diagnostic outcomes in childhood anxiety over traditional child-only ICBT. While this is possibly the case, there are also several alternative explanations for the current results.

\section{Alternative explanations to current findings.}

The limitations of the current meta-analytic review also need to be considered when interpreting the present findings. Primarily, while the immediately post-treatment analysis returned a non-significant result, there was also a significant and moderate to large amount of heterogeneity found for this analysis. This suggests that there were considerable differences between the studies that were included in this meta-analysis and that they may have been testing different underlying effects or have substantial variance due to sampling error (Hanji, 2017). When heterogeneity between studies is moderate to large (as it is here) it is suggested that results given by a meta-analysis may not be representative of the true underlying effect which could, in reality, be lower or higher than the observed effect (Borenstein et al., 2011). 
While the heterogeneity tests employed here only make these assessments based on the studies' sample sizes and calculated odds ratios, there are also considerable differences between the included studies which can be identified by reviewing Table 1 . These include differences in samples, aims, methodologies and treatment interventions and may be contributing to the heterogeneity observed here. To prevent these differences causing significant heterogeneity in future meta-analyses it is suggested that future studies within the area employ a more standardised approach to their methodologies. This may involve using standardised PCBT and ICBT interventions, conducting multi-center RCTs that involve diverse participant samples and thoroughly reporting methodology details. To resolve the heterogeneity caused by sampling error more studies were needed to be included in the analysis. Future research replicating the current meta-analyses with a more comprehensive search of the existing literature is recommended.

Additionally, the current study analysed the effectiveness of PCBT and ICBT on diagnostic anxiety data. While being free from diagnosis is the objective of all childhood anxiety treatments it does not provide a precise measure of treatment effects. Many of the included studies also employed additional measures of treatment efficacy such as measures of quality of life, child behaviours and collateral reports from the child's parents and teachers (see Table 1 for a full list of additional measures). These additional measures can provide a more precise and detailed representation of the effects of a treatment. Therefore, it remains unclear if PCBT is more or equally as effective than ICBT on quality of life and symptom severity. It was not possible to examine this in the current study because the included studies measured different outcome variables. Thus, it is recommended that future research within the area consider measuring symptom severity and quality of life in addition to measuring diagnostic outcomes. This will allow for more precise and detailed analysis of effectiveness at not only the individual study level but also in any subsequent meta-analyses. 
Because previous studies predominately focused on the role of mothers in PCBT (Parke, 2004 \& Verhoeven et al., 2012), it was reasoned that the exclusion of fathers might explain the mixed and unexpected results within the existing literature (James et al, 2015). It is further recommended that future research compare the effects of PCBT with mothers and fathers to the existing literature containing a mother or one parent only PCBT. Doing this would allow for an evaluation of the unique contribution that fathers have in treatment and could provide further insight into the inconsistent findings of both the existing literature and the current study.

\section{Moderators of the Current and Existing Findings}

Furthermore, the current study did not consider the effects of possible moderators that could alter the magnitude and direction of the efficacy of PCBT and ICBT. These moderators include but are not limited to: the level of parental involvement in their child's life, (b) the presence or level of parental anxiety, and (c) the anxious child's attachment and relationship with their parents. These three moderators are possible factors contributing to the uncertainty in both the existing literature and the current meta-analytic findings. It may be possible that the current null findings are a false negative result as these moderators could not be considered in the present analyses.

The potential for the level of parental involvement to moderate the effects of PCBT was considered by Manassis et al. (2014). Manassis et al. (2014) show that the effects of parental involvement in the lives of their children on treatment outcome is moderated by the amount and quality of the parental involvement with more involvement and higher quality involvement resulting in better treatment outcomes for their children. However, this study did not distinguish between mother and father involvement. It is recommended that future studies consider the effect of parent-child relationship variables on treatment outcomes for children. 
Cobham et al. (1998) noted that many initial studies including parents in treatment did so in an attempt to mitigate the parental factors that contribute to the development and maintenance of childhood anxiety. Testing the parental anxiety moderator Cobham et al. (1998) found that the addition of a parent-focused component to CBT for anxious children resulted in better diagnostic outcomes for those children who had one or both parent suffering from anxiety. Parental anxiety may be a moderating factor in the current study, however, it was one which was not able to be explored due to time constraints on the current study. Thus, it is recommended that future studies consider the role of parental anxiety on treatment outcomes for children.

Additionally, the anxious child's attachment and relationship with their parents may also moderate the magnitude and direction of any PCBT effect. Previously it was reasoned that attachment theory provides a rationale for including parents in childhood anxiety treatments (Bogels and Phares, 2008). However, there is limited research testing the influence of such a moderator and further research should be conducted to assess how such a moderate would impact treatment outcomes for childhood anxiety.

The non-significant and null findings of the current meta-analytic study also conflict with some previous research, such as that by Brendel and Maynard (2013), and Manassis et al. (2014). Both studies found an advantage of including parents in CBT based treatments for childhood anxiety when it was compared to ICBT but only once they combined the nonsignificant results of multiple smaller studies via meta-analyses. Moreover, these two studies made no explicit effort to ensure both mothers and fathers were involved. However, they still provide considerable support for an advantage for childhood anxiety treatments that involve parents over child-only treatments. While it remains to be shown that PCBT with both mothers and fathers is more effective that ICBT, where possible the involvement of both parents in a PCBT childhood anxiety treatment is still recommended due to the unique 
contributions mothers and fathers make to children's social-emotional development (Bogels, \& Phares, 2008).

\section{Implications for Practice}

While the current meta-analytic review has a number of limitations, it still provides several implications for future practice in both the research and clinical fields. Several recommendations for future research of both the RCT and meta-analytic variety have already been discussed and are as follows:

- Research involving a parental element should detail explicitly the number of mothers and fathers involved, to allow for both clinicians and researchers to better understand the study and its generalisability. This applies not only to research concerning PCBT and childhood anxiety but any study involving mothers and fathers.

- Future comparisons of PCBT and ICBT should also include a control condition to compare with active treatment conditions, allowing for more accurate efficacy assessments.

- Studies exploring childhood anxiety treatment should employ not only a diagnostic outcome measure but also a quality of life or symptom severity measure. This will allow for efficacy analyses to be considered across studies beyond diagnostic recovery rates.

- Research comparing the effects of PCBT with mother and father involvement should also be compared to mother-only and/or one parent-only PCBT, allowing for an evaluation of the unique influences of mothers and fathers in treatment.

- Any replication of current meta-analyses should also consider the potential moderators including not only those discussed here (level of parental involvement, child-parent attachment, and parental anxiety) but also any others identified elsewhere within the literature. 
These recommendations culminate to suggest that future research should aim to be more detailed, explicit and systematic in their research as well as aim to address the voids in research that have been identified here.

Should the recommended future research corroborate the current findings that both PCBT (even when both parents are involved) and ICBT are equally efficacious treatments then these findings suggest that in practice clinicians treating anxious children can make decisions to involve mothers and fathers in CBT on a case-by-case basis, depending on the anxious child's needs and abilities. However, the outcomes of the future research suggested here may also influence these case-by-case decisions. For example, if the level of parental involvement, attachment, or anxiety is evidenced to moderate the effects of PCBT then clinicians may be able to better tailor their treatment of the child's anxiety to their individual family characteristics.

Furthermore, there will be further implications for practicing clinicians should future research show that PCBT is a significantly more efficacious treatment than ICBT. Firstly, it would be important to consider the magnitude of this effect and the real-world differences it represents for the anxious child. If such an effect was of considerable magnitude, then the relevant evidence would need to be disseminated to not only practicing clinicians but also to the relevant clinical education programs. Additionally, should research support this PCBT advantage it would also be imperative that future research on the moderating conditions of this effect be conducted. This will help guide clinicians on how they should approach including parents in treatment in ways which will enable to obtain the significant advantages observed in research. Moreover, should this PCBT advantage be found for childhood anxiety treatment then research should also investigate if a similar effect is also found for other childhood conditions. Conversely, should an advantage for ICBT be found then research into the potential moderating factors that apply to ICBT should also be conducted. Additionally, 
further research into why ICBT has an advantage should also be considered, not just empirically but also on a theoretical level. Additionally, should either treatment condition be found to be more effective than the other future research should also consider the costeffectiveness for these treatments, as the potential difference in effectiveness may be outweighed by the affordability of the treatments.

In conclusion, the current study observed that PCBT (with mother and father involvement) was equally effective as child-only ICBT. It is recommended that clinicians base their childhood anxiety treatment decisions on the individual needs of the child and their family. Future research is also needed, and the current study's findings as they are discussed here will be of value to future researchers. The present findings are limited in their implications for clinicians and have some considerable methodological limitations. The present discussion of these limitations has also considered how they can be addressed in future research and used to enhance the quality and utility of future findings. Thus, while the present study was not able to provide any evidence of support for a PCBT advantage it has initiated a discussion on how future research can resolve the existing literature’s unclear findings. 


\section{References}

References marked with an asterisk indicate studies included in the present meta-analyses.

Adler Nevo, G. W., Avery, D., Fiksenbaum, L., Kiss, A., Mendlowitz, S., Monga, S., \& Manassis, K. (2014). Eight years later: Outcomes of CBT-treated versus untreated anxious children. Brain and Behavior, 4(5), 765-774. doi:10.1002/brb3.274

American Psychiatric Association. (2013). Anxiety Disorders. In Diagnostic and Statistical Manual of Mental Disorders (5 ${ }^{\text {th }}$ ed.). Arlington, VA: American Psychiatric Publishing. doi:10.1176/appi.books.9780890425596

Australian Bureau of Statistics. (2016). Causes of Death, Australia (Report No. 3303.0). Retrieved from: http://www.abs.gov.au/ausstats/abs@.nsf/Lookup/by\%20Subject/3303.0 2016 Main\%20 Features $\sim$ Summary\%20of\%20findings $\sim 1$

Aydin, A. (2014). Parental involvement in cognitive-behavioral therapy for children with anxiety disorders. Turk Psikiyatri Dergisi, 25(3), 181-189.

Barrett, P. M. (1998). Evaluation of cognitive-behavioral group treatments for childhood anxiety disorders. Journal of Clinical Child Psychology, 27(4), 459-468. doi: 10.1207/s1537424jccp2704_10

Barrett, P. M., Duffy, A. L., Dadds, M. R., \& Rapee, R. M. (2001). Cognitive-behavioral treatment of anxiety disorders in children: Long-term (6-year) follow-up. Journal of Consulting and Clinical Psychology, 69(1), 135-141. doi: 10.1037//0022-006x.69.1.135

Barrett, P. M., Rapee, R. M., \& Dadds, M. R. (1996). Family treatment of childhood anxiety: A controlled trial. Journal of Consulting and Clinical Psychology, 64(2), 333-342. doi: 10.1037//0022-006x.64.2.333 
Bodden, D. H., Bogels, S. M., Nauta, M. H., De Haan, E., Riingrose, J., Appelboom, C., . . . Appelboom-Geerts, K. C. (2008). Child versus family cognitive-behavioral therapy in clinically anxious youth: An efficacy and partial effectiveness study. Journal of the American Academy of Child Adolescent Psychiatry, 47(12), 1384-1394. doi: 10.1097/chi.ob013e318189148e

*Bodden, D. H. M., Dirksen, C. D., Bogels, S. M., Nauta, M. H., De Haan, E., Ringrose, J., . . . Appelboom-Geerts, K. C. M. M. J. (2008). Costs and cost-effectiveness of family CBT versus individual CBT in clinically anxious children. Clinical Child Psychology and Psychiatry, 13(4), 543-564. doi:10.1177/1359104508090602

Bogels, S., \& Phares, V. (2008). Fathers' role in the etiology, prevention and treatment of child anxiety: A review and new model. Clinical Psychology Review, 28(4), 539-558. doi:10.1016/j.cpr.2007.07.011

Bornstein, M. H. (2002). Handbook of Parenting: Volume 3 Being and Becoming a Parent: Taylor \& Francis.doi: 10.1097/00004703-200404000-00011

Borenstein, M., Hedges, L. V., Higgins, J. P. T., \& Rothstein, H. R. (2011). Introduction to Meta-Analysis: Wiley. doi: 10.1002/9780470743386

Brendel, K. E., \& Maynard, B. R. (2014). Child-Parent Interventions for Childhood Anxiety Disorders: A Systematic Review and Meta-Analysis. Research on Social Work Practice, 24(3), 287-295. doi:10.1177/1049731513503713

Cartwright-Hatton, S., Roberts, C., Chitsabesan, P., Fothergill, C., \& Harrington, R. (2004). Systematic review of the efficacy of cognitive behaviour therapies for childhood and adolescent anxiety disorders. British Journal of Clinical Psychology, 43(4), 421-436. doi: 10.1348/0144665042388928 
Cobham, V., Dadds, M., \& Spence, S. (1998). The role of parental anxiety in the treatment of childhood anxiety. Journal of Consulting and Clinical Psychology, 66(6), 893-905. doi: 10.1037//0022-006x.66.6.893

Creswell, C., \& Cartwright-Hatton, S. (2007). Family treatment of child anxiety: Outcomes, limitations and future directions. Clinical Child and Family Psychology Review, 10(3), 232-252. doi: 10.1007/s10567-007-0019-3

Dowell, K. A., \& Ogles, B. M. (2010). The Effects of Parent Participation on Child Psychotherapy Outcome: A Meta-Analytic Review. Journal of Clinical Child and Adolescent Psychology, 39(2), 151-162. doi:10.1080/15374410903532585

Hanji, M. B. (2017). Meta-Analysis in Psychiatry Research: Fundamental and Advanced Methods. Apple Academic Press. doi:10.1201/9781315366234

Higgins, J. P., \& Green, S. (2011). Cochrane Handbook for Systematic Reviews of Interventions. Version 5.1.0. The Cochrane Collaboration. Available from: www.cochrnaehandbook.org. doi: 10.1002/9780470712184

Higgins, J. P., Thompson, S. G., Deeks, J. J., \& Altman, D. G. (2003). Measuring inconsistency in meta-analyses. British Medical Journal, 327(7414), 557-560. doi:10.1136/bmj.327.7414.557

Hudson, J. L., \& Rapee, R. M. (2001). Parent-child interactions and anxiety disorders: an observational study. Behaviour Research and Therapy, 39(12), 1411-1427. doi:https://doi.org/10.1016/S0005-7967(00)00107-8

James, A. C., James, G., Cowdrey, F. A., Soler, A., \& Choke, A. (2015). Cognitive behavioural therapy for anxiety disorders in children and adolescents. Cochrane Database of Systematic Reviews(2). doi:10.1002/14651858.CD004690.pub4 
Jongerden, L., \& Bogels, S. M. (2015). Parenting, family functioning and anxiety-disordered children: Comparisons to controls, changes after family versus child CBT. Journal of Child and Family Studies, 24(7), 2046-2059. doi: 10.1007/s10826-014-0005-6

Kendall, P., Flannery-Schroeder, E., Panichelli-Mindel, S., Southam-Gerow, M., Henin, A., \& Warman, M. (1997). Therapy for youths with anxiety disorders: a second randomized clinical trial. Journal of Consulting and Clinical Psychology, 65(3), 366-380. doi: 10.1037/0022-006x.65.3.366

*Kendall, P. C., Hudson, J. L., Gosch, E., Flannery-Schroeder, E., \& Suveg, C. (2008). Cognitive-Behavioral Therapy for Anxiety Disordered Youth: A Randomized Clinical Trial Evaluating Child and Family Modalities. Journal of Consulting and Clinical Psychology, 76(2), 282-297. doi: 10.1037/0022-006x.76.2.282

Khanna, M., \& Kendall, P. (2009). Exploring the role of parent training in the treatment of childhood anxiety. Journal of Consulting and Clinical Psychology, 77(5), 981-986. doi:10.1037/a0016920

Manassis, K., Changgun Le, T., Bennett, K., Zhao, X. Y., Mendlowitz, S., Duda, S., . . Wood, J. J. (2014). Types of parental involvement in CBT with anxious youth: A preliminary meta-analysis. Journal of Consulting and Clinical Psychology, 82(6), 1163-1172. doi: 10.1037/a0036969

*Marin, C. E. (2011). Parental involvement and group cognitive behavioral treatment for anxiety disorders in children and adolescents: Treatment specificity and mediation effects of parent and peer variables. Dissertation Abstracts International Section A: Humanities and Social Sciences, 71(12-A), 4597. doi:

Matthewson, M., Smith, R. B., \& Montgomery, I. (2012). Does the Parent-Child Relationship Contribute to Children's and Parents’ Anxiety?. Journal of Relationships Research, 3, 19. doi: $10.1017 / j r r .2012 .2$ 
Matthewson, M. L. (2009). Do mothers and fathers differentially contribute to sons' and daughters' anxiety?.

Moher, D., Liberati, A., Tetzlaff, J., Altman, D. G., \& The, PRISMA Group. (2009). Preferred Reporting Items for Systematic Reviews and Meta-Analyses: The PRISMA Statement. PLOS Medicine, 6(7), e1000097. doi:10.1371/journal.pmed.1000097

Nauta, M., Scholing, A., Emmelkamp, P., \& Minderaa, R. (2003). Cognitive-behavioral therapy for children with anxiety disorders in a clinical setting: no additional effect of a cognitive parent training. Journal of the American Academy of Child and Adolescent Psychiatry, 42(11), 1270-1278. doi:10.1097/01.chi.0000085752.71002.93

Pereira, A. I., Muris, P., Mendonca, D., Barros, L., Goes, A. R., \& Marques, T. (2016). Parental involvement in cognitive-behavioral intervention for anxious children: Parents' in-session and out-session activities and their relationship with treatment outcome. Child Psychiatry and Human Development, 47(1), 113-123. doi: 10.1007/s10578-015-0549-8

Podell, J. L., \& Kendall, P. C. (2011). Mothers and fathers in family cognitive-behavioral therapy for anxious youth. Journal of Child and Family Studies, 20(2), 182-195. doi: 10.1007/s10826-010-9420-5

Parke, R., D. (2004). Fathers, Families, and the Future: A Plethora of Plausible Predictions. Merrill-Palmer Quarterly 4, 456-470. doi: 10.1353.mpq.2004.0033

Review Manager (RevMan5) Version (5.3) [Computer program]. Copenhagen: The Nordic Cochrane Centre, The Cochrane Collaboration, 2014.

*Schneider, S., Blatter-Meunier, J., Herren, C., In-Albon, T., Adornetto, C., Meyer, A., \& Lavallee, K. L. (2013). The efficacy of a family-based cognitive-behavioral treatment for separation anxiety disorder in children aged 8-13: A randomized comparison with a general anxiety program. Journal of Consulting and Clinical Psychology, 81(5), 932-940. doi: $10.1037 / \mathrm{a} 0032678$ 
Schneider, S., Unnewehr, S., \& Margraf, J. (2009). Kinder-DIPS for DSM-IV-TR: Diagnostic Interview for Psychological Disorders of Childhood and Youth. Heidelberg, Germany: Springer. doi:10.1007/978-3-662-006607-2_3

Silverman, W. K., Kurtines, W. M., Jaccard, J., \& Pina, A. A. (2009). Directionality of Change in Youth Anxiety Treatment Involving Parents: An Initial Examination. Journal of Consulting and Clinical Psychology, 77(3), 474-485. doi: 10.037/a0015761

Silverman, W. K., \& Nelles, W. B. (1988). The Anxiety Disorders Interview Schedule for Children. Journal of the American Academy of Child \& Adolescent Psychiatry, 27(6), 772-778. doi:https://doi.org/10.1097/00004583-198811000-00019

*Simon, E., Bogels, S. M., \& Voncken, J. M. (2011). Efficacy of Child-Focused and ParentFocused Interventions in a Child Anxiety Prevention Study. Journal of Clinical Child and Adolescent Psychology, 40(2), 204-219. doi:10.1080/15374416.2011.546039

Simpson, H. B. (2010). Anxiety disorders: theory, research, and clinical perspectives. Cambridge: Cambridge University Press, 2010. doi: 10.1017/s0033291711001851 Siqueland, L., Rynn, M., \& Diamond, G. S. (2005). Cognitive behavioral and attachment based family therapy for anxious adolescents: Phase I and II studies. Journal of Anxiety Disorders, 19(4), 361-381. doi:10.1016/j.janxdis.2004.04.006

Slade, T., Johnston, A., Teesson, M., Whiteford, H., Burgess, P., Pirkis, J., Saw, S. (2009). The Mental Health of Australians 2. Report on the 2007 National Survey of Mental Health and Wellbeing. Department of Health and Ageing, Canberra. doi: 10.1037/e676562010001

Verhoeven, M., Bogels, S. M., \& van der Bruggen, C. C. (2012). Unique Roles of Mothering and Fathering in Child Anxiety; Moderation by Child's Age and Gender. Journal of Child and Family Studies, 21(2), 331-343. doi:10.1007/s10826-011-9483-y 
Wei, C. Y., \& Kendall, P. C. (2014). Parental Involvement: Contribution to Childhood Anxiety and Its Treatment. Clinical Child and Family Psychology Review, 17(4), 319-339. doi:10.1007/s10567-014-0170-6

Wood, J. J., Piacentini, J. C., Southam-Gerow, M., Chu, B. C., \& Sigman, M. (2006). Family cognitive behavioral therapy for child anxiety disorders. Journal of the American Academy of Child and Adolescent Psychiatry, 45(3), 314-321. doi:

10.1097/01.chi.0000196425.88341.b0

Yap, M. B., \& Jorm, A. F. (2015). Parental factors associated with childhood anxiety, depression, and internalizing problems: a systematic review and meta-analysis. Journal of Affective Disorders, 175, 424-440. doi:10.1016/j.jad.2015.01.050 
Appendix A

PRISMA checklist for the current systematic review and meta-analyses

\begin{tabular}{|c|c|c|c|}
\hline Section/topic & $\#$ & Checklist item & $\begin{array}{l}\text { Reported } \\
\text { on page \# }\end{array}$ \\
\hline \multicolumn{4}{|l|}{ TITLE } \\
\hline Title & 1 & Identify the report as a systematic review, meta-analysis, or both. & 1 \\
\hline \multicolumn{4}{|l|}{ ABSTRACT } \\
\hline Structured summary & 2 & $\begin{array}{l}\text { Provide a structured summary including, as applicable: background; objectives; data sources; study eligibility criteria, } \\
\text { participants, and interventions; study appraisal and synthesis methods; results; limitations; conclusions and } \\
\text { implications of key findings; systematic review registration number. }\end{array}$ & 2 \\
\hline \multicolumn{4}{|l|}{ INTRODUCTION } \\
\hline Rationale & 3 & Describe the rationale for the review in the context of what is already known. & $3-11$ \\
\hline Objectives & 4 & $\begin{array}{l}\text { Provide an explicit statement of questions being addressed with reference to participants, interventions, comparisons, } \\
\text { outcomes, and study design (PICOS). }\end{array}$ & $10-11$ \\
\hline \multicolumn{4}{|l|}{ METHODS } \\
\hline Protocol and registration & 5 & $\begin{array}{l}\text { Indicate if a review protocol exists, if and where it can be accessed (e.g., Web address), and, if available, provide } \\
\text { registration information including registration number. }\end{array}$ & $\mathrm{N} / \mathrm{A}$ \\
\hline Eligibility criteria & 6 & $\begin{array}{l}\text { Specify study characteristics (e.g., PICOS, length of follow-up) and report characteristics (e.g., years considered, } \\
\text { language, publication status) used as criteria for eligibility, giving rationale. }\end{array}$ & 12 \\
\hline Information sources & 7 & $\begin{array}{l}\text { Describe all information sources (e.g., databases with dates of coverage, contact with study authors to identify } \\
\text { additional studies) in the search and date last searched. }\end{array}$ & 10 \\
\hline Search & 8 & $\begin{array}{l}\text { Present full electronic search strategy for at least one database, including any limits used, such that it could be } \\
\text { repeated. }\end{array}$ & $51-55$ \\
\hline Study selection & 9 & $\begin{array}{l}\text { State the process for selecting studies (i.e., screening, eligibility, included in systematic review, and, if applicable, } \\
\text { included in the meta-analysis). }\end{array}$ & $12-13$ \\
\hline Data collection process & 10 & $\begin{array}{l}\text { Describe method of data extraction from reports (e.g., piloted forms, independently, in duplicate) and any processes } \\
\text { for obtaining and confirming data from investigators. }\end{array}$ & 14 \\
\hline Data items & 11 & $\begin{array}{l}\text { List and define all variables for which data were sought (e.g., PICOS, funding sources) and any assumptions and } \\
\text { simplifications made. }\end{array}$ & $15-17$ \\
\hline $\begin{array}{l}\text { Risk of bias in individual } \\
\text { studies }\end{array}$ & 12 & $\begin{array}{l}\text { Describe methods used for assessing risk of bias of individual studies (including specification of whether this was } \\
\text { done at the study or outcome level), and how this information is to be used in any data synthesis. }\end{array}$ & 14 \\
\hline Summary measures & 13 & State the principal summary measures (e.g., risk ratio, difference in means). & 17 \\
\hline Synthesis of results & 14 & $\begin{array}{l}\text { Describe the methods of handling data and combining results of studies, if done, including measures of consistency } \\
\left(\text { e.g., }\left.\right|^{2} \text { ) for each meta-analysis. }\right.\end{array}$ & $17-19$ \\
\hline
\end{tabular}


Appendix A

\begin{tabular}{|c|c|c|c|}
\hline Section/topic & $\#$ & Checklist item & $\begin{array}{l}\text { Reported } \\
\text { on page \# }\end{array}$ \\
\hline Risk of bias across studies & 15 & $\begin{array}{l}\text { Specify any assessment of risk of bias that may affect the cumulative evidence (e.g., publication bias, selective } \\
\text { reporting within studies). }\end{array}$ & 14 \\
\hline Additional analyses & 16 & $\begin{array}{l}\text { Describe methods of additional analyses (e.g., sensitivity or subgroup analyses, meta-regression), if done, indicating } \\
\text { which were pre-specified. }\end{array}$ & 15 \\
\hline \multicolumn{4}{|l|}{ RESULTS } \\
\hline Study selection & 17 & $\begin{array}{l}\text { Give numbers of studies screened, assessed for eligibility, and included in the review, with reasons for exclusions at } \\
\text { each stage, ideally with a flow diagram. }\end{array}$ & 13,20 \\
\hline Study characteristics & 18 & $\begin{array}{l}\text { For each study, present characteristics for which data were extracted (e.g., study size, PICOS, follow-up period) and } \\
\text { provide the citations. }\end{array}$ & 21 \\
\hline Risk of bias within studies & 19 & Present data on risk of bias of each study and, if available, any outcome level assessment (see item 12). & $\begin{array}{l}24,27 \\
29,57\end{array}$ \\
\hline Results of individual studies & 20 & $\begin{array}{l}\text { For all outcomes considered (benefits or harms), present, for each study: (a) simple summary data for each } \\
\text { intervention group (b) effect estimates and confidence intervals, ideally with a forest plot. }\end{array}$ & 27,29 \\
\hline Synthesis of results & 21 & Present results of each meta-analysis done, including confidence intervals and measures of consistency. & $25-29$ \\
\hline Risk of bias across studies & 22 & Present results of any assessment of risk of bias across studies (see Item 15). & 24,57 \\
\hline Additional analysis & 23 & Give results of additional analyses, if done (e.g., sensitivity or subgroup analyses, meta-regression [see Item 16]). & 30 \\
\hline \multicolumn{4}{|l|}{ DISCUSSION } \\
\hline Summary of evidence & 24 & $\begin{array}{l}\text { Summarize the main findings including the strength of evidence for each main outcome; consider their relevance to } \\
\text { key groups (e.g., healthcare providers, users, and policy makers). }\end{array}$ & $32-35$ \\
\hline Limitations & 25 & $\begin{array}{l}\text { Discuss limitations at study and outcome level (e.g., risk of bias), and at review-level (e.g., incomplete retrieval of } \\
\text { identified research, reporting bias). }\end{array}$ & 33-39 \\
\hline Conclusions & 26 & Provide a general interpretation of the results in the context of other evidence, and implications for future research. & $39-41$ \\
\hline \multicolumn{4}{|l|}{ FUNDING } \\
\hline Funding & 27 & $\begin{array}{l}\text { Describe sources of funding for the systematic review and other support (e.g., supply of data); role of funders for the } \\
\text { systematic review. }\end{array}$ & N/A \\
\hline
\end{tabular}

Note: PRISMA Checklist modified for the current study with corresponding page numbers. Original from: Moher, D., Liberati, A., Tetzlaff, J., Altman, D. G., \& The PRISMA Group. (2009). Preferred Reporting Items for Systematic Reviews and Meta-Analyses: The PRISMA Statement. PLOS Medicine, 6(7), e1000097. doi: 10.1371/journal.pmed.1000097 
Appendix B

Search terms for the Cochrane Library

\section{Cochrane L Library}

Trusted evidence.

Informed decisions.

Better health.

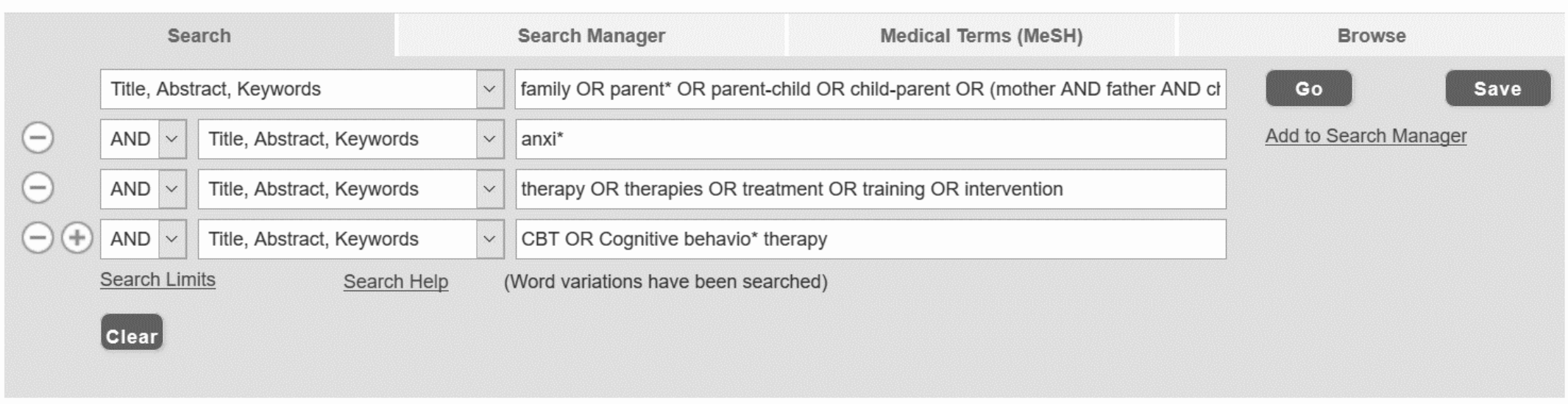

All Results (400)

- Cochrane Reviews (28)

- All

Review

Protocol

\section{Cochrane Database of Systematic Reviews : Issue 5 of 12, May 2017}

Issue updated daily throughout month

There are $\mathbf{2 8}$ results from $\mathbf{9 8 3 9}$ records for your search on 'family OR parent* OR parent-child OR child-parent OR (mother AND father AND child*) in Title, Abstract, Keywords and anxi* in Title, Abstract, Keywords and therapy OR therapies OR treatment OR training OR intervention in Title, Abstract, Keywords and CBT OR Cognitive behavio* therapy in Title,

Note: Search terms used for the current studies literature search of the Cochrane Library database. 
Appendix B

Search terms for Embase

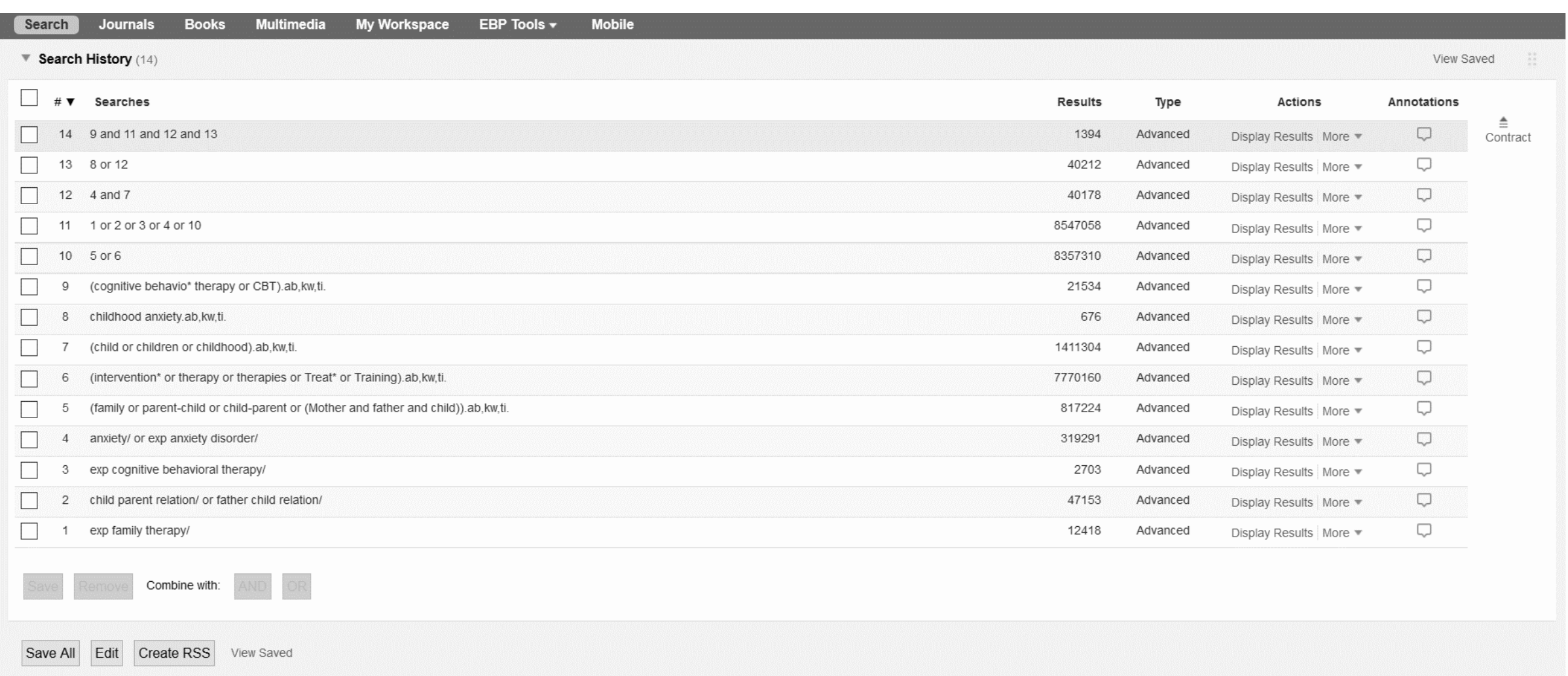

Note: Search terms used for the current studies literature search of the Embase database. 
Appendix B

Search terms for PsychINFO

\begin{tabular}{|c|c|c|c|c|c|c|c|}
\hline$\square$ & $\# \mathbf{~}$ & Searches & Results & Type & Actions & & Annotations \\
\hline$\square$ & 21 & 7 and 10 and 17 and 19 and 20 & 214 & Advanced & Display Results & More ${ }^{-}$ & $\square$ \\
\hline$\square$ & 20 & 11 or 19 & 19721 & Advanced & Display Results & More - & $\square$ \\
\hline$\square$ & 19 & 12 and 18 & 19283 & Advanced & Display Results & More - & $\square$ \\
\hline$\square$ & 18 & 8 or 9 & 126909 & Advanced & Display Results & More - & $\square$ \\
\hline$\square$ & 17 & 1 or 2 or 4 or 14 or 16 & 129816 & Advanced & Display Results & More ${ }^{-}$ & $\square$ \\
\hline$\square$ & 16 & parent child relations/ or exp father child relations/ & 29933 & Advanced & Display Results & More - & $\square$ \\
\hline$\square$ & 15 & 1 or 2 or 3 or 4 or 14 & 129829 & Advanced & Display Results & More - & $\square$ \\
\hline$\square$ & 14 & 5 and 6 & 95697 & Advanced & Display Results & More - & $\square$ \\
\hline$\square$ & 13 & 1 or 2 or 3 or 4 & 55603 & Advanced & Display Results & More - & $\square$ \\
\hline$\square$ & 12 & (child or children or childhood).ab,ti. & 575239 & Advanced & Display Results & More $\mathbf{r}$ & $\square$ \\
\hline$\square$ & 11 & "child" anxi"".ab,ti. & 2245 & Advanced & Display Results & More $\mathbf{v}$ & $\square$ \\
\hline$\square$ & 10 & (CBT or cognitive behavio* therapy).ab,ti. & 18985 & Advanced & Display Results & More $\mathbf{v}$ & $\square$ \\
\hline$\nabla$ & 9 & exp anxiety disorders/ & 72493 & Advanced & Display Results & More - & $\square$ \\
\hline$\nabla$ & 8 & exp anxiety/ & 61317 & Advanced & Display Results & More $\mathbf{V}$ & $\square$ \\
\hline$\nabla$ & 7 & exp cognitive behavior therapy/ & 16755 & Advanced & Display Results & More $\mathbf{v}$ & $\square$ \\
\hline$\nabla$ & 6 & (intervention* or therapy or therapies or Treat" or Training).ab,ti. & 1079035 & Advanced & Display Results & More $\mathbf{v}$ & $\square$ \\
\hline$\nabla$ & 5 & (family or parent-child or child-parent or (Mother and father and child)).ab,ti. & 273410 & Advanced & Display Results & More - & $\square$ \\
\hline$\square$ & 4 & exp family therapy/ & 20726 & Advanced & Display Results & More $\mathbf{v}$ & $\square$ \\
\hline$\nabla$ & 3 & parent child relations/ or father child relations.mp. [mp=title, abstract, heading word, table of contents, key concepts, original title, tests \& measures] & 29951 & Advanced & Display Results & More - & $\square$ \\
\hline$\square$ & 2 & parental involvement/ & 4495 & Advanced & Display Results & More - & $\square$ \\
\hline$\square$ & 1 & family intervention/ & 2651 & Advanced & Display Results & More $\mathbf{v}$ & $\square$ \\
\hline
\end{tabular}

Note: Search terms used for the current studies literature search of the PsychINFO database. 
Appendix B

Search terms for PubMed

History

Download history Clear history

\begin{tabular}{|c|c|c|c|c|}
\hline Search & Add to builder & Query & Items found & Time \\
\hline \#8 & $\underline{\text { Add }}$ & $\begin{array}{l}\text { Search ((((CBT OR cognitive behavio* therapy)) AND (child OR childhood OR children)) AND anxi*) } \\
\text { AND (treatment OR therapy OR therapies OR training OR intervention)) AND (parent OR (mother AND } \\
\text { father AND child) OR parent-child OR child-parent) }\end{array}$ & $\underline{421}$ & $20: 55: 31$ \\
\hline$\# 7$ & $\underline{\text { Add }}$ & 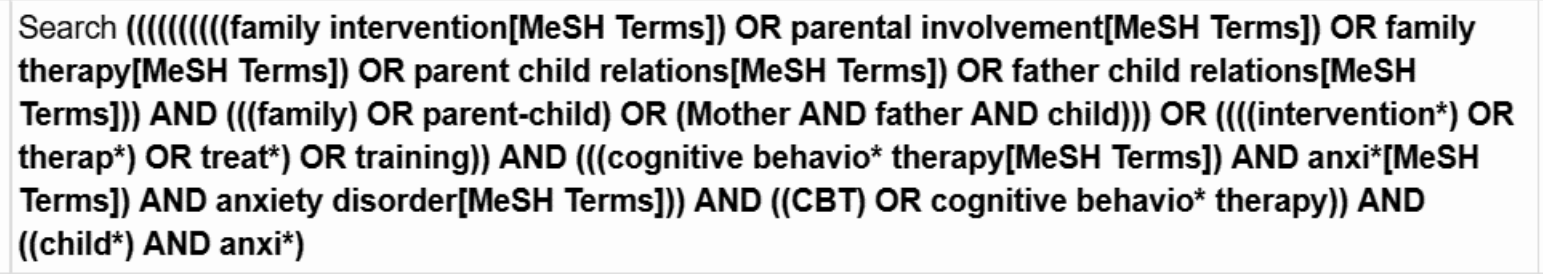 & $\underline{9}$ & $20: 50: 42$ \\
\hline$\underline{\# 6}$ & $\underline{\text { Add }}$ & Search $\left(\right.$ child $\left.^{\star}\right)$ AND anxi* & $\underline{35453}$ & $20: 49: 05$ \\
\hline$\underline{\# 5}$ & $\underline{\text { Add }}$ & Search (CBT) OR cognitive behavio* therapy & $\underline{19021}$ & $20: 48: 43$ \\
\hline$\# 4$ & $\underline{\text { Add }}$ & $\begin{array}{l}\text { Search ((cognitive behavio* therapy[MeSH Terms]) AND anxi*[MeSH Terms]) AND anxiety } \\
\text { disorder[MeSH Terms] }\end{array}$ & $\underline{60}$ & $20: 48: 20$ \\
\hline$\# 3$ & $\underline{\text { Add }}$ & Search ((intervention*) OR therap*) OR treat*) OR training & $\underline{7656429}$ & $20: 47: 03$ \\
\hline$\# 2$ & $\underline{\text { Add }}$ & Search ((family) OR parent-child) OR (Mother AND father AND child) & $\underline{1061103}$ & $20: 46: 08$ \\
\hline$\# 1$ & $\underline{\text { Add }}$ & $\begin{array}{l}\text { Search ((((family intervention[MeSH Terms]) OR parental involvement[MeSH Terms]) OR family } \\
\text { therapy[MeSH Terms]) OR parent child relations[MeSH Terms]) OR father child relations[MeSH Terms] }\end{array}$ & $\underline{57032}$ & $20: 44: 52$ \\
\hline
\end{tabular}

Note: Search terms used for the current studies literature search of the PubMed database. 


\section{Appendix B}

\section{Search terms for the Web of Science}

\section{Search History: Web of Science ${ }^{\mathrm{TM}}$ Core Collection}

\begin{tabular}{|c|c|c|c|c|c|}
\hline & & & & Combine Sets & Delete Sets \\
\hline Set & Results & Save History / Create Alert & Sets & & Select All \\
\hline & & & & Combine & $\times$ Delete \\
\hline \# 8 & 554 & $\begin{array}{l}\text { \#7 AND \#6 AND \#3 } \\
\text { Indexes=SCl-EXPANDED, SSCI, A\&HCl, CPCl-S, CPCI-SSH, ESCI, CCR-EXPANDED, IC Timespan=All years }\end{array}$ & Edit & $\square$ & $\square$ \\
\hline \# 7 & 34,836 & $\begin{array}{l}\text { TOPIC: (cognitive behavio* therapy) OR TOPIC: (CBT) } \\
\text { Indexes=SCI-EXPANDED, SSCI, A\&HCI, CPCI-S, CPCI-SSH, ESCI, CCR-EXPANDED, IC Timespan=All years }\end{array}$ & Edit & $\square$ & $\square$ \\
\hline \# 6 & 30,237 & $\begin{array}{l}\# 5 \text { AND \#4 } \\
\text { Indexes=SCl-EXPANDED, SSCl, A\&HCl, CPCl-S, CPCl-SSH, ESCl, CCR-EXPANDED, IC Timespan=All years }\end{array}$ & Edit & $\square$ & $\square$ \\
\hline$\# 5$ & 196,199 & $\begin{array}{l}\text { TOPIC: (anxiety) } \\
\text { Indexes=SCl-EXPANDED, SSCI, A\&HCl, CPCI-S, CPCI-SSH, ESCI, CCR-EXPANDED, IC Timespan=All years }\end{array}$ & Edit & $\square$ & $\square$ \\
\hline \# 4 & $1,424,381$ & $\begin{array}{l}\text { TOPIC: (child) OR TOPIC: (children) OR TOPIC: (childhood) } \\
\text { Indexes=SCl-EXPANDED, SSCI, A\&HCl, CPCI-S, CPCl-SSH, ESCI, CCR-EXPANDED, IC Timespan=All years }\end{array}$ & Edit & $\square$ & $\square$ \\
\hline \#3 & 196,241 & $\begin{array}{l}\text { \#2 AND \#1 } \\
\text { Indexes=SCI-EXPANDED, SSCl, A\&HCl, CPCl-S, CPCl-SSH, ESCI, CCR-EXPANDED, IC Timespan=All years }\end{array}$ & Edit & $\square$ & $\square$ \\
\hline \#2 & $5,873,900$ & $\begin{array}{l}\text { TOPIC: (intervention) OR TOPIC: (therapy) OR TOPIC: (therapies) OR TOPIC: (treatment) OR TOPIC: (training) } \\
\text { Indexes=SCI-EXPANDED, SSCI, A\&HCI, CPCI-S, CPCI-SSH, ESCI, CCR-EXPANDED, IC Timespan=All years }\end{array}$ & Edit & $\square$ & $\square$ \\
\hline \#1 & $1,178,221$ & $\begin{array}{l}\text { TOPIC: (family) OR TOPIC: (parent-child) OR TOPIC: (child-parent) OR TOPIC: (mother AND father AND child) } \\
\text { Indexes=SCI-EXPANDED, SSCI, A\&HCI, CPCI-S, CPCI-SSH, ESCI, CCR-EXPANDED, IC Timespan=All years }\end{array}$ & Edit & $\square$ & $\square$ \\
\hline & & & & OAND $\bigcirc$ OR & Select All \\
\hline & & & & Combine & $\times$ Delete \\
\hline
\end{tabular}

Note: Search terms used for the current studies literature search of the Web of Science database. 
Appendix C

Data extraction form

\begin{tabular}{|l|l|}
\hline Citation \\
\hline $\begin{array}{l}\text { General information } \\
\text { (publication type, } \\
\text { country of study, } \\
\text { funding and funding } \\
\text { conflicts) }\end{array}$ \\
\hline $\begin{array}{l}\text { Study Design } \\
\text { Inclusion/exclusion } \\
\text { criteria }\end{array}$ \\
\hline Participants \\
\hline $\begin{array}{l}\text { Quality Assessment } \\
\text { hamitations, } \\
\text { data, biases, or } \\
\text { withdrawals/attrition }\end{array}$ \\
\hline $\begin{array}{l}\text { Specific } \\
\text { intervention }\end{array}$
\end{tabular}

Note: Sample of the data extraction form used for the current studies systematic extraction of data from the included studies. 


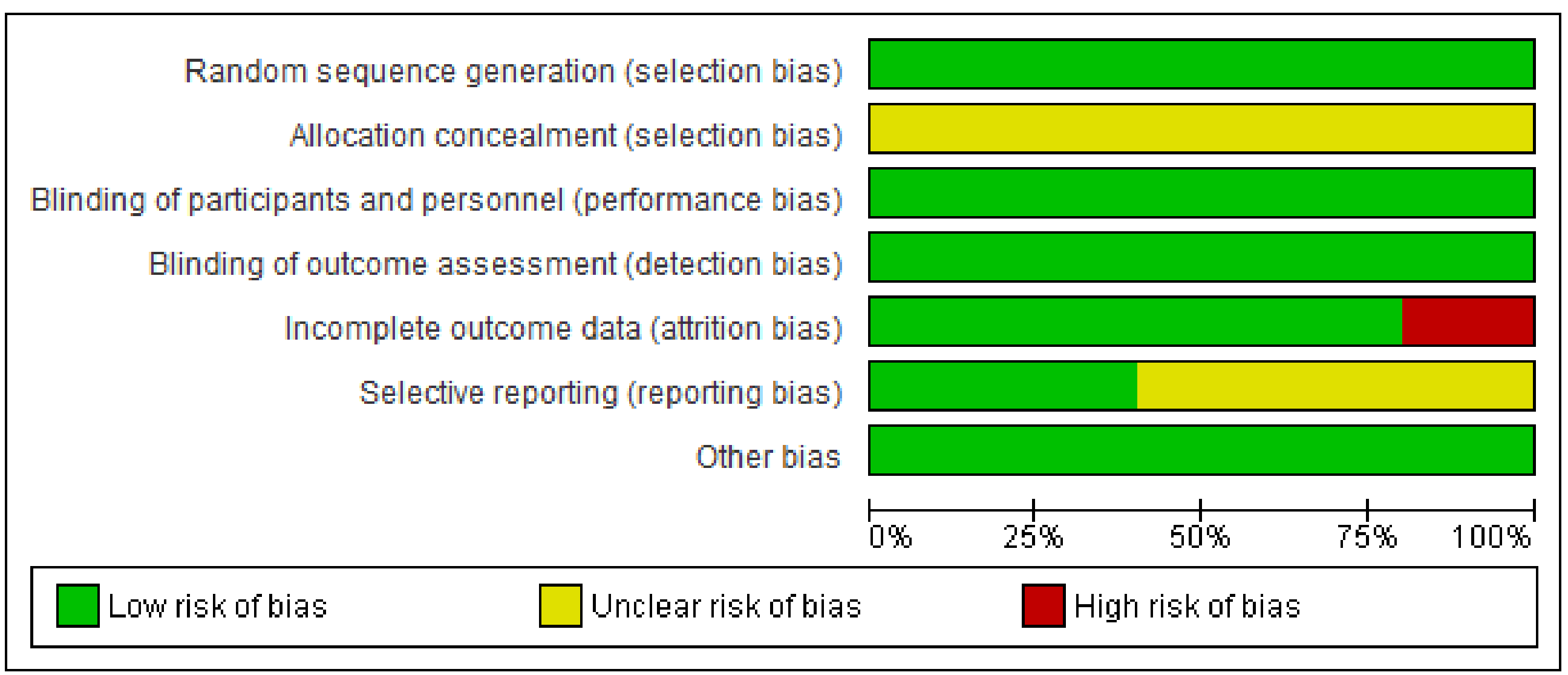

Note: A graph depicting the predominately low overall risk of bias for the studies included in the current systematic review and metaanalyses. 